\title{
Dabigatran - a case history demonstrating the need for comprehensive approaches to optimize the use of new drugs
}

Rickard E. Malmström ${ }^{1}$, Brian B. Godman ${ }^{2,3,4}$ *, Eduard Diogene ${ }^{5}$, Christoph Baumgärtel ${ }^{6}$, Marion Bennie ${ }^{4,7}$, lain Bishop 7 , Anna Brzezinska ${ }^{8}$, Anna Bucsics $^{9}$, Stephen Campbell ${ }^{10}$, Alessandra Ferrario ${ }^{11}$, Alexander E. Finlayson ${ }^{12}$, Jurij Fürst ${ }^{13}$, Kristina Garuoliene ${ }^{14}$, Miguel Gomes ${ }^{15}$, Iñaki Gutiérrez-Ibarluzea ${ }^{16}$, Alan Haycox ${ }^{3}$, Krystyna Hviding ${ }^{17}$, Harald Herholz ${ }^{18}$, Mikael Hoffmann ${ }^{19}$, Saira Jan ${ }^{20}$, Jan Jones ${ }^{21}$, Roberta Joppi ${ }^{22}$, Marija Kalaba ${ }^{23}$, Christina Kvalheim ${ }^{17}$, Ott Laius ${ }^{24}$, Irene Langner ${ }^{25}$, Julie Lonsdale ${ }^{26}$, Sven-Åke Lööv ${ }^{27}$, Kamila Malinowska ${ }^{28,29}$, Laura McCullagh ${ }^{30}$, Ken Paterson ${ }^{31}$, Vanda Markovic-Pekovic ${ }^{32,33}$, Andrew Martin ${ }^{34}{ }^{t}$, Jutta Piessnegger ${ }^{9}$, Gisbert Selke ${ }^{24}$, Catherine Sermet ${ }^{35}$, Steven Simoens ${ }^{36}$, Cankat Tulunay ${ }^{37}$,Dominik Tomek ${ }^{38,39}$, Luka Vončina ${ }^{40}$, Vera Vlahovic-Palcevski ${ }^{41}$, Janet Wale ${ }^{42}$, Michael Wilcock ${ }^{43}$, Magdalena Wladysiuk ${ }^{28}$, Menno van Woerkom ${ }^{44}$, Corrine Zara ${ }^{45}$ and Lars L. Gustafsson ${ }^{2}$

${ }^{1}$ Clinical Pharmacology Unit, Department of Medicine, Karolinska Institutet, Karolinska University Hospital Solna, Stockholm, Sweden

${ }^{2}$ Division of Clinical Pharmacology, Department of Laboratory Medicine, Karolinska Institutet, Karolinska University Hospital Huddinge, Stockholm, Sweden

${ }^{3}$ Liverpool Health Economics Centre, University of Liverpool, Liverpool, UK

${ }^{4}$ Strathclyde Institute for Pharmacy and Biomedical Sciences, University of Strathclyde, Glasgow, UK

${ }^{5}$ Unitat de Coordinació i Estratégia del Medicament, Direcció Adjunta d'Afers Assistencials, Catalan Institute of Health, Barcelona, Spain

${ }^{6}$ Austrian Medicines and Medical Devices Agency, Wien, Austria

7 Information Services Division, NHS National Services Scotland, Edinburgh, UK

${ }^{8}$ Agency for Health Technology Assessment, Warsaw, Poland

${ }^{9}$ Hauptverband der Österreichischen Sozialversicherungsträger, Wien, Austria

${ }^{10}$ Centre for Primary Care, Institute of Population Health, University of Manchester, Manchester, UK

${ }^{11}$ London School of Economics and Political Sciences, LSE Health, London, UK

${ }^{12}$ King's Centre for Global Health, Global Health Offices, Weston Education Centre, London, UK

${ }^{13}$ Health Insurance Institute, Ljubljana, Slovenia

${ }^{14}$ Medicines Reimbursement Department, National Health Insurance Fund, Vilnius, Lithuania

15 Instituto Nacional da Farmácia e do Medicamento, Lisboa, Portugal

${ }^{16}$ Osteba Basque Office for Health Technology Assessment, Ministry of Health of the Basque Country, Donostia-San Sebastian, Vitoria-Gasteiz, Basque Country, Spain

${ }_{17}$ Norwegian Medicines Agency, Oslo, Norway

${ }^{18}$ Kassenärztliche Vereinigung Hessen, Frankfurt am Main, Germany

${ }^{19}$ Nätverk för läkemedelsepidemiologi, Department of Health Analysis, University Hospital, Linköping, Sweden

${ }^{20}$ Clinical Programs, Pharmacy Management, Horizon Blue Cross Blue Shield of New Jersey, Newark, USA

${ }^{21}$ Ninewells Hospital, NHS Tayside, Dundee, UK

22 Pharmaceutical Department, Local Health Unit of Verona, Verona, Italy

${ }^{23}$ Republic Institute for Health Insurance, Belgrade, Serbia

${ }^{24}$ State Agency of Medicines, Tartu, Estonia

${ }^{25}$ Wissenschaftliches Institut der AOK, Berlin, Germany

${ }^{26}$ Lancashire Commissioning Support Unit, Jubilee House, Leyland, Lancashire, UK

${ }^{27}$ Department of Healthcare Development, Stockholm County Council, Stockholm, Sweden

${ }^{28}$ HTA Consulting, Cracow, Poland

${ }^{29}$ Public Health School, The Medical Centre of Postgraduate Education, Warsaw, Poland

${ }^{30}$ National Centre for Pharmacoeconomics, St James's Hospital, Dublin, Ireland

${ }^{31}$ Scottish Medicines Consortium, Glasgow, UK

${ }_{32}$ Faculty of Medicine, University of Banja Luka, Banja Luka, Bosnia and Herzegovina, Republic of Srpska

${ }_{33}$ Ministry of Health and Social Welfare, Banja Luka, Bosnia and Herzegovina, Republic of Srpska

${ }^{34}$ NHS Bury, Bury, UK

${ }^{35}$ Institut de Recherche et Documentation en Économie de la Santé, Paris, France

${ }^{36}$ KU Leuven Department of Pharmaceutical and Pharmacological Sciences, Leuven, Belgium

${ }_{37}$ President of the Turkish Rational Drug Use Platform, Ankara, Turkey

${ }^{38}$ Faculty of Pharmacy, Comenius University, Bratislava, Slovakia

${ }^{39}$ Faculty of Medicine, Slovak Medical University, Bratislava, Slovakia

${ }^{40}$ Ministry of Health, Zagreb, Republic of Croatia

${ }^{41}$ Unit for Clinical Pharmacology, University Hospital Rijeka, Rijeka, Croatia

42 Independent Consumer Advocate, Brunswick, VIC, Australia

${ }^{43}$ Prescribing Support Unit, clo Pharmacy Department, Royal Cornwall Hospitals NHS Trust, Truro, Cornwall, UK

${ }^{44}$ Dutch Institute for Rational Use of Medicine, Utrecht, Netherlands

${ }^{45}$ Barcelona Health Region, Catalan Health Service, Barcelona, Spain 


\section{Edited by:}

Dominique J. Dubois, Université Libre de Bruxelles, Belgium

\section{Reviewed by:}

Mark J. C. Nuijten, Ars Accessus Medica BV, Netherlands

Zoltan Kalo, Health Economics

Research Centre; Eötvös Loránd

University, Hungary

\section{*Correspondence:}

Brian B. Godman, Division of Clinical Pharmacology, Department of Laboratory Medicine, Karolinska Institutet, Karolinska University Hospital, C1:68, Huddinge, SE-141 86 Stockholm, Sweden.

e-mail: brian.godman@ki.se

${ }^{\dagger}$ Present address:

Andrew Martin, NHS Greater

Manchester Commissioning Support Unit, Salford, UK.
Background: There are potential conflicts between authorities and companies to fund new premium priced drugs especially where there are safety and/or budget concerns. Dabigatran, a new oral anticoagulant for the prevention of stroke in patients with non-valvular atrial fibrillation (AF), exemplifies this issue. Whilst new effective treatments are needed, there are issues in the elderly with dabigatran due to variable drug concentrations, no known antidote and dependence on renal elimination. Published studies have shown dabigatran to be cost-effective but there are budget concerns given the prevalence of AF. There are also issues with potentially re-designing anticoagulant services. This has resulted in activities across countries to better manage its use.

Objective: To (i) review authority activities in over 30 countries and regions, (ii) use the findings to develop new models to better manage the entry of new drugs, and (iii) review the implications for all major stakeholder groups.

Methodology: Descriptive review and appraisal of activities regarding dabigatran and the development of guidance for groups through an iterative process.

Results: There has been a plethora of activities among authorities to manage the prescribing of dabigatran including extensive pre-launch activities, risk sharing arrangements, prescribing restrictions, and monitoring of prescribing post-launch. Reimbursement has been denied in some countries due to concerns with its budget impact and/or excessive bleeding. Development of a new model and future guidance is proposed to better manage the entry of new drugs, centering on three pillars of pre-, peri-, and post-launch activities.

Conclusion: Models for introducing new drugs are essential to optimize their prescribing especially where there are concerns. Without such models, new drugs may be withdrawn prematurely and/or struggle for funding.

Keywords: critical drug evaluation, dabigatran, demand-side measures, drug and therapeutics committees, managed introduction new medicines, pharmacovigilance, registries, risk sharing

\section{BACKGROUND}

New medicines are of real value to patients when they improve their health either because they are more effective, have less side-effects, or are easier to administer than current standards. European health authorities also wish new drugs to be costeffective (Garattini et al., 2008; Godman et al., 2008, 2009c, 2012d; Wettermark et al., 2008, 2010a; Coma et al., 2009; Sermet et al., 2010; Garuoliene et al., 2011b; Voncina and Strizrep, 2011; Vončina et al., 2011; Cheema et al., 2012; Markovic-Pekovic et al., 2012). Continued pressure on resources is already resulting in some countries unable to fund new premium priced drugs (Garuoliene et al., 2011a,b; Godman et al., 2011c, 2012b; Taylor, 2011), with the number of countries likely to increase with new drugs now being launched at US\$300,000 (€228,000) per patient per year or more (Kaiser, 2012). Premium prices are of concern among authorities struggling to maintain, and potentially incompatible with, the European ideals of comprehensive and equitable healthcare (Garattini et al., 2008; Adamski et al., 2010; Godman et al., 2012b).

This may result in conflicts between authorities and pharmaceutical companies with the latter keen to re-coup the considerable monies spent on research and development as soon as possible through rapid reimbursement (DiMasi and Grabowski, 2007; Abraham, 2008; Jaroslawski and Toumi, 2011; Persson et al., 2012) as well as maintain profitability with established products (Shuchman, 2006; Abraham, 2008; Godman et al., 2010, 2011b, 2012b; Vončina etal., 2011; Baumgärtel et al., 2012; Jackevicius etal.,
2012). However, this can be at odds with the aims of health authorities and health insurance companies struggling to meet European ideals within available resources (Shuchman, 2006; Abraham, 2008; Garattini et al., 2008; Godman et al., 2010, 2011b, 2012b; Sermet et al., 2010; Garuoliene et al., 2011b; Voncina and Strizrep, 2011; Vončina et al., 2011; Baumgärtel et al., 2012; Ozierański et al., 2012). Marketing activities are seen as important by companies to achieve their aims in an increasingly competitive environment (Civaner, 2012); but these can involve considerable spending. Published studies suggest marketing costs can be as high as one-third of a company's income (Civaner, 2012), with companies spending US\$53bn ( $€ 40.2)$ in the US alone in 2004 marketing to physicians (Lexchin and Kohler, 2011; Godman et al., 2012b; Godman and Gustafsson, 2013). In addition, there have been concerns with aggressive lobbying and other indirect strategies by some companies (Mello et al., 2012; Ozierański et al., 2012), as well as with some of the marketing (Department of Justice, 2010; Griffin and Segal, 2010; Lexchin and Kohler, 2011; Fisk et al., 2012; Davies and Abraham, 2013) and other activities (Jackevicius et al., 2012; Baumgärtel et al., 2012; Ozierański et al., 2012; Davies and Abraham, 2013) to achieve their aims. This is despite the imposition of multi-million dollar fines (Davies and Abraham, 2013).

These conflicts can be greater when there are safety concerns with new drugs, and they are subsequently prescribed in a wider population than studied in randomized clinical trials. Typically Phase III clinical trials are conducted under ideal and highly controlled conditions to seek high internal validity to maximize the 
chance of demonstrating clinical benefit (Fritz and Cleland, 2003). However, this may lead to substantial differences from their subsequent use in clinical practice. Typically Phase III clinical trials do not include treatment preferences and/or multimodal treatment programs (Wells, 1999; Guthrie, 2000; Fritz and Cleland, 2003). Phase III clinical trials may also include a placebo group as a comparator in order to isolate the effects of a particular intervention (Fritz and Cleland, 2003). These situations can lead to concerns with the generalizability of the findings when new drugs are being considered as an alternative to current treatments, especially once prescribed in patients with greater co-morbidities than those enrolled into Phase III clinical trials.

For example, both cerivastatin and mibefradil had favorable benefit-risk profiles at market authorization, but their use in clinical practice, coupled with physicians ignoring recommended guidance, caused their withdrawal from the market (Friedman et al., 1999; Eichler et al., 2011). Previously in the 1980s zimelidine, the first selective serotonin re-uptake inhibitor, was withdrawn from the market due to hypersensitivity reactions and febrile reactions in connection to liver function disturbances, which later evolved into Guillain-Barré syndrome (GBS; Carlson, 1999, 2000). This withdrawal might have been avoided if zimelidine had been introduced in a stepwise fashion, as there was an average increase of GBS-risk of 25 -fold among patients receiving zimelidine compared with the natural incidence of the disorder (Fagius et al., 1985).

Rofecoxib was also withdrawn following growing evidence of increased cardiovascular events such as heart attacks and stroke with long-term treatment (Merck, 2004; MHRA UK, 2004). Rofecoxib was seen as the most selective COX-II inhibitor among the first generation of this class with minimal COX-I activity (Davies and Jamali, 2004). Whilst this reduces gastrointestinal (GI) side-effects, this also reduced the cardioprotective effect of COX-I inhibitors that is similar to low-dose aspirin (Davies and Jamali, 2004; Bresalier et al., 2005). This protective effect of COX-I inhibitors led to a reduction in the risk of thrombotic cardiovascular events in patients treated with naproxen compared to rofecoxib (Reicin etal., 2001; Weir etal., 2003; Davies and Jamali, 2004), documented in the VIGOR study (Bombardier et al., 2000). The study specifically excluded patients who were taking concomitant aspirin or other antiplatelet drugs such as those with a recent history of myocardial infarction or stroke (Bombardier et al., 2000; Merck, 2002). The findings led to a caution being added to the product label in May 2002 in patients with a medical history of ischemic heart disease (FDA, 2002; Merck, 2002). The concerns with increased cardiovascular events associated with long-term rofecoxib therapy also led to the instigation of the APPROVe study (Bresalier et al., 2005). The findings of increased cardiovascular risk with rofecoxib (Bresalier et al., 2005) subsequently led to its withdrawal (Davies and Jamali, 2004; Merck, 2004; MHRA UK, 2004). There are ongoing debates whether the withdrawal of rofecoxib may have been avoided if there had not been appreciable marketing activities, including considerable direct to consumer advertising in the US, promoting the safety of COX-II inhibitors (Calfee and Pinell, 2005).

Natalizumab was withdrawn soon after its launch despite improved effectiveness in patients with relapsing multiple sclerosis. This was due to the development of progressive multifocal leukoencephalopathy (PML) in some patients (Kappos et al., 2011; Keegan, 2011). However, it was re-launched some 2 years later in Europe, but under strict prescribing regulations and with the instigation of research programs to clarify the benefit:risk ratios (Kappos et al., 2011; Keegan, 2011). More recently, rimonabant has been withdrawn from the market. Patients prescribed rimonabant experienced a higher incidence of anxiety, depression, and insomnia (Moreira et al., 2009; O'Shaughnessy, 2009; Ioannides-Demos et al., 2011). This led to advice that patients prescribed rimonabant should be investigated first for psychiatric illness and that rimonabant should not be prescribed in patients with mental illness (Moreira et al., 2009; O'Shaughnessy, 2009; Ioannides-Demos et al., 2011). However, this advice was sometimes ignored leading to its withdrawal due to increased risk of depression and suicidal ideation (European Medicines Agency [EMA], 2009; Godman et al., 2009c; Dietrich and Horvath, 2012; Wong et al., 2012). It may be that greater knowledge of the role of the hypothalamus in enabling the central nervous system to adapt to the changing environment could facilitate the discovery of new agents that are more effective and have a more acceptable benefit-risk profile (Wong et al., 2012). However, this remains to be seen.

New oral anticoagulants (NOACs) illustrate some of these tensions as they show promise in the prevention of stroke in patients with atrial fibrillation (AF), offering an alternative to warfarin without the need for INR (International Normalized Ratio) monitoring (Baetz and Spinler, 2008; Connolly et al., 2009; Malmström, 2009; Pink etal., 2011; Scottish Medicines Consortium, 2011; Banerjee et al., 2012; Godman et al., 2012d; Kansal et al., 2012; Mannuci et al., 2012; National Institute for Health and Clinical Excellence, 2012; Davidson et al., 2013; Joppi et al., 2013; Marshall et al., 2013; Rodriguez et al., 2013). This is in addition to venous thromboembolism prophylaxis for patients undergoing hip and knee surgery, and in the treatment of acute deep vein thrombosis and pulmonary embolism (Marshall et al., 2013). However, there are safety concerns especially in the elderly (Malmström, 2009; Pink et al., 2011; Godman et al., 2012d; Mannuci et al., 2012; Stollberger and Finsterer, 2013) in addition to potential compliance (Marshall et al., 2013; Rodriguez et al., 2013) and storage issues (Stollberger and Finsterer, 2013).

Atrial fibrillation is the most common clinically significant cardiac arrhythmia with an estimated prevalence of $1-2 \%$ of the population (Marshall etal., 2013). One in four adults over the age of 40 is likely to develop AF in their lifetime, higher in those aged over 80 (Lloyd-Jones et al., 2004; Stewart et al., 2004; Camm et al., 2010; Pink et al., 2011; Mannuci et al., 2012; Davidson et al., 2013). Current estimates suggest there are 4.5 million people in Europe with AF and 3.03 million in the US (Marshall et al., 2013), with the prevalence of AF likely to double in the next 50 years with ageing populations (Go et al., 2001; Stewart et al., 2001, 2004; Lloyd-Jones et al., 2004; Luengo-Fernandez et al., 2006; Kirchhof et al., 2007; Connolly et al., 2009; Camm etal., 2010; Pink et al., 2011; Marshall et al., 2013). New drugs are needed since patients with $\mathrm{AF}$ have a fivefold increased risk of cardioembolic stroke compared with those in sinus rhythm (Stewart et al., 2004; Camm et al., 2010; Pink et al., 2011), with a cardioembolic stroke resulting in 
approximately $20 \%$ of patients dying in the acute phase and $60 \%$ developing severe disability (Mannuci et al., 2012). Incurred costs also tend to be higher in stroke patients with AF, with those patients who survive left more disabled by their stroke and more likely to have a recurrence than those with other causes of stroke (LuengoFernandez et al., 2006; Camm et al., 2010; Kansal etal., 2012). Initial incurred secondary care costs averaged GB£9667/patient (2005 costs) in patients with AF compared with an average of GBE5824 in other stroke patients (Luengo-Fernandez et al., 2006). As a consequence, the risk of death from AF related strokes is doubled compared with other forms of stroke, and the overall cost of care increased 1.5-fold (Kirchhof et al., 2007; Camm et al., 2010; Scottish Medicines Consortium, 2011; National Institute for Health and Clinical Excellence, 2012). Anticoagulant therapy with vitamin $\mathrm{K}$ antagonists (VKAs) can reduce by at least $60 \%$ the risk of stroke (Camm et al., 2010; Mannuci et al., 2012). However, there are concerns with warfarin due to the potential of bleeding, the need to tailor doses to the individual with too high a dose potentially causing serious complications and too low a dose losing protection, and the difficulties with maintaining some patients within INRs (Pink etal., 2011; Mannuci et al., 2012; Marshall et al., 2013).

Dabigatran received EU marketing authorization in August 2011 (Boehringer Ingelheim, 2011a; Marshall et al., 2013) for the prevention of stroke and systemic embolism/clot formation in adult patients with non-valvular AF with one or more of the following risk factors:

- Previous stroke, transient ischemic attack, or systemic embolism/clot formation

- Left ventricular ejection fraction $<40 \%$

- Symptomatic heart failure > New York Heart Association (NYHA) Class 2

- Age $>75$ years

- Age $>65$ years in combination with additional vascular risk, i.e., patients with diabetes mellitus, coronary artery disease, or arterial hypertension

Published studies showed a 9\% reduction in the prevention of stroke or systemic embolism with dabigatran $110 \mathrm{mg}$ twice daily and 34\% for the $150 \mathrm{mg}$ twice daily (Horsley, 2010; Mannuci et al., 2012; Davidson et al., 2013; Marshall et al., 2013). Overall mortality was also reduced by $12 \%$ for the highest dose of dabigatran, which reached statistical significance (Horsley, 2010; Mannuci et al., 2012). There was also an appreciable and consistent reduction in the risk of hemorrhagic stroke ranging from 69 to $74 \%$ depending on the dose of dabigatran (Horsley, 2010; Pink et al., 2011; Mannuci et al., 2012), with the $150 \mathrm{mg}$ twice daily dose of dabigatran also providing a statistical significant reduction in ischemic stroke (24\% risk reduction; Horsley, 2010; Pink et al., 2011; Mannuci et al., 2012). Dabigatran could also potentially require no monitoring compared with warfarin (Pink et al., 2011; Godman et al., 2012d; Mannuci et al., 2012; Marshall et al., 2013). As a result, dabigatran has the potential to be an important new treatment, especially where regular monitoring with warfarin is problematic or where there are adverse events or other patient issues with warfarin.
These improvements, coupled with potential savings with dabigatran with the opportunity to reduce patient monitoring, resulted in incremental cost-effectiveness ratios (ICERs) of GB£4831 (€5560)/quality adjusted life year (QALY) in patients under 80 versus warfarin and GB£7090 (€8150) above 80 (Kansal et al., 2012). A similar study in Sweden estimated the cost/QALY gained for dabigatran versus warfarin as $€ 7742$, increasing to $€ 12,449$ in patients who were well controlled with warfarin (Davidson etal., 2013). Other authors have published higher ICERs, i.e., GB£23,082 ( $€ 26,700) / Q A L Y$ for high dose dabigatran versus warfarin (Pink etal., 2011; Scottish Medicines Consortium, 2011; Marshall etal., 2013). The manufacturer's submission to the Scottish Medicines Consortium (SMC) suggested a cost/QALY of GBE6986 (€8030) versus warfarin. This estimate was based on the sequencing of dabigatran, starting with $150 \mathrm{mg}$ twice daily for patients under the age of 80 who were subsequently switched to $110 \mathrm{mg}$ twice daily when they reached 80 years (Scottish Medicines Consortium, 2011). The ICER increased to GB£13,347 (€15,350) when the model was adjusted to lower the potential savings from reduced INR monitoring to a more appropriate figure (Scottish Medicines Consortium, 2011; Marshall et al., 2013). The Evidence Review Group (ERG) of the National Institute for Health and Clinical Excellence (NICE) also had concerns with the model provided by the manufacturer and the cost of anticoagulation therapy (National Institute for Health and Clinical Excellence, 2012; Marshall etal., 2013). Under different assumptions, the ERG believed the base case ICER for dabigatran $150 \mathrm{mg}$ twice daily increased from GB£6264 (€7200) to GB£24,173-29,131 (€27,790-33,490)/QALY (National Institute for Health and Clinical Excellence, 2012). This was due to two main weaknesses in the submitted model (National Institute for Health and Clinical Excellence, 2012). These included the lack of any potential switching of treatment from dabigatran back to warfarin as well as an overstatement of the costs of monitoring patients prescribed warfarin in practice (National Institute for Health and Clinical Excellence, 2012). There were also concerns that patient heterogeneity would be greater in practice than allowed for in the submitted models (National Institute for Health and Clinical Excellence, 2012; Marshall et al., 2013). However, both organizations recommended dabigatran as an alternative to warfarin in patients who meet the criteria outlined in the marketing authorization (Scottish Medicines Consortium, 2011; National Institute for Health and Clinical Excellence, 2012; Marshall et al., 2013), with NICE also recommending that dabigatran should only be prescribed after an informed discussion between clinicians and patients (National Institute for Health and Clinical Excellence, 2012). The National Centre for Pharmacoeconomics (NCPE) in Ireland recently concluded that the ICER for dabigatran versus warfarin was $€ 6311 /$ QALY in patients under 80 years and $€ 20,654 /$ QALY in patients 80 years or older. Extracranial hemorrhage was an important cost driver (versus warfarin in those 80 years and over) and disability costs were important across all comparisons (National Centre for Pharmacoeconomics, 2011).

However, there have been concerns with the rapid introduction of dabigatran, which led to an appreciable number of 
serious adverse events with the first 12 weeks of availability in the US (Institute for Safe Medication Practices, 2011). These were principally serious bleeding events or blood clots in the elderly (Institute for Safe Medication Practices, 2011). These concerns and others led the FDA to explore correlating reductions in stroke events with increasing plasma correlations alongside bleeding event rates (Thompson, 2010), with the guidance available when dabigatran was launched in Europe. In addition, re-examining and comparing the bleeding rates with warfarin and dabigatran (Southworth et al., 2013). These concerns have arisen due to dabigatran's low mean oral bioavailability, considerable variation in plasma drug concentrations, and the complete dependence on renal elimination of the active metabolite (Stangier et al., 2008; Stangier and Clemens, 2009; Thompson, 2010; Liesenfeld et al., 2011; Douxfils et al., 2012; Huisman et al., 2012; Mannuci et al., 2012; Ten Cate, 2012). Consequently, any accumulation of dabigatran in patients with reduced renal function will increase their risk of excessive bleeding (Malmström, 2009; Legrand et al., 2011; Pink et al., 2011; Garber et al., 2012; Godman et al., 2012d; Harper etal., 2012; Huisman etal., 2012; Mannuci et al., 2012; Ten Cate, 2012), complicated by no known antidote (Rolfe et al., 2010; Institute for Safe Medication Practices, 2011; Pink et al., 2011; Godman et al., 2012d; Huisman et al., 2012; Mannuci et al., 2012; Marshall et al., 2013). This is important in this situation as patients in clinical practice are likely to be more elderly, have greater co-morbidities, and have reduced hepatic and renal functions, compared to the patients in the clinical trials (Joppi et al., 2013). There are also concerns with its budget impact given the growing prevalence of AF (Pink et al., 2011; Godman et al., 2012d; Midlands Therapeutic Review and Advisory Committee [MTRAC], 2012; Marshall et al., 2013). A number of health authorities across Europe have recognized these issues and initiated extensive pre- and peri-launch programs to educate physicians and the public regarding the optimal use of dabigatran, especially in elderly patients with poor renal function.

The principal objective of this paper is to review health authority and health insurance company activities across Europe pre-launch to post-launch of dabigatran for the prevention of stroke as an exemplar for developing future models to better manage the entry of new premium priced drugs. Subsequently, to use these strategies to suggest future activities that all key stakeholder groups could undertake to reduce the likelihood of new drugs being removed from the market place where there are concerns with their use in a wider patient population. Finally, to suggest activities that better manage expenditure on new drugs where there are concerns with their budget impact. This is important as concerns with the budget impact of new drugs are growing. This especially given the number of new drugs in development including new biological drugs (EvaluatePharma, 2012; Godman, 2013), which are now costing up to US\$10,000-25,000 (€758018,960) per patient per month (Selyukh, 2011; Yukhananov, 2011; Godman etal., 2012b; Kaiser, 2012; UK Medicines Information, 2012; UKMi Medicines Information, 2013). This potentially inhibits the ability of governments to continue to provide equitable and comprehensive healthcare within current budgets.

\section{METHODOLOGY}

A descriptive review of national, regional or local health authority, health insurance company or physician association activities across Europe regarding dabigatran up to and including the beginning of 2013 was conducted by one of the co-authors (Brian B. Godman). This was undertaken by collating and appraising relevant published papers and internal documents known to the co-authors as well as any pertinent documents available on the internet. Direct feedback was provided by the co-authors where there was limited or no data available in a particular country. The information provided by the co-authors was subsequently re-checked (Brian B. Godman) to enhance its accuracy. In total, information was collected from over 30 European countries and regions. We have used this methodological approach in previous publications involving health authority and health insurance company personnel when there has been a paucity of published data (Cheema et al., 2012; Godman et al., 2011b,c, 2010, 2012a,b; Adamski et al., 2010; Baumgärtel et al., 2012). The countries were chosen to provide differences in geography, epidemiology, financing of healthcare, available resources for healthcare as well as different approaches to the pricing and reimbursement of new drugs (Godman et al., 2008, 2010, 2011b, 2012d; Wettermark et al., 2008, 2010a; Coma et al., 2009; Sermet et al., 2010; Garuoliene et al., 2011a,b; Voncina and Strizrep, 2011; Cheema et al., 2012; Markovic-Pekovic et al., 2012; Godman and Gustafsson, 2013). This included both national and regional authorities in some countries, recognizing ongoing budget devolution, e.g., England, Scotland, Spain, and Sweden, as well as differences with the organization and funding of anticoagulant services.

Demand-side initiatives and reforms were collated under four different activities named the four Es - Education, Engineering, Economics, and Enforcement (Wettermark et al., 2009a) - to provide comparisons with measures used to improve the quality and efficiency of the prescribing of existing drugs across Europe (Godman et al., 2009b,c, 2010, 2011a,b, 2012b,c,f; Wettermark et al., 2009a,b, 2010b; World Health Organisation, 2009; McGinn et al., 2010; Gustafsson et al., 2011; Vončina et al., 2011; Baumgärtel et al., 2012; Bennie et al., 2012; Kalaba et al., 2012; Markovic-Pekovic et al., 2012; Medicine Balance [MEDICIJNBALANS], 2012; van Woerkom et al., 2012); they include:

- Educational activities - these range from simple distribution of printed material to intensive strategies including academic detailing and monitoring of prescribing habits usually by professional medical networks. Examples include local, regional, and national formularies, guidance and guidelines including those from Drug and Therapeutic Committees

- Engineering activities - organizational or managerial issues to influence change, e.g., quality and efficiency prescribing targets

- Economic interventions - financial incentives. These include financial incentives for physicians if they achieve agreed prescribing targets in a class, devolution of drug budgets to local GP groups combined with regular monitoring of prescribing behavior, as well as fines for prescribing costs above agreed limits. Initiatives also include patient co-payments, especially if patients wish a more expensive product than the current reference priced product for the molecule (Anatomical Chemical 
Therapeutic - ATC - Level 5) or the class/group (ATC Level 3 or 4)

- Enforcement - regulations by law such as compulsory International Non-proprietary Name (INN) prescribing, compulsory generic substitution, or prescribing restrictions such as those instigated for patented statins in Austria, Finland, and Norway and the angiotensin receptor blockers (ARBs) in Austria, Croatia, Lithuania, the Republic of Srpska, and Sweden

No attempt has been made to critique the initiatives, including comparing and contrasting the potential influence of the multiple initiatives across the countries and regions to provide future guidance. This is because this would require a thorough analysis of drug utilization patterns alongside associated health policies (Coma et al., 2009; Godman et al., 2009b, 2010, 2011a,b, 2012c; Wettermark et al., 2009b, 2010b; McGinn et al., 2010; Garuoliene et al., 2011b; Vončina et al., 2011; Bennie et al., 2012; Kalaba et al., 2012; Markovic-Pekovic et al., 2012; van Woerkom et al., 2012). This will be undertaken in future research projects. However, documented initiatives were used to derive suggested models and potential guidance for all key topics and stakeholder groups to improve the managed entry of new drugs in the future. Initial models and draft guidance were subsequently amended and refined through an iterative process. This involved several rounds with the co-authors until all co-authors were satisfied and agreed with the proposed new model and guidance provided.

\section{RESULTS}

\section{HEALTH AUTHORITY AND HEALTH INSURANCE COMPANY ACTIVITIES}

Table 1 summarizes some of the health authority/health insurance company activities pre-, peri-, and post-launch up till the end of 2012. Unless stated, the indications are those contained in the EMA marketing authorization (Boehringer Ingelheim, 2011a; European Medicines Agency [EMA], 2008; EMA, 2012; Marshall et al., 2013). Table A1 in the Appendix provides a comprehensive summary of examples from regions and countries across Europe.

Similarly in Australia, the Department of Health and Ageing in the Ministry of Health recently undertook a review of NOACs in the management of stroke risk in patients with AF (Australian Government Department of Health and Ageing, 2012). They recommended to the Pharmaceutical Benefits Advisory Committee (PBAC) the following based on their belief that the net overall benefit of NOACs in clinical practice, and the subsequent impact on cost-effectiveness, is uncertain at this stage:

- Initiating a managed entry scheme taking into account the identified uncertainties while acknowledging the clinical need for effective alternatives to warfarin. This includes the entry price that addresses the uncertainties

- New oral anticoagulants are only reimbursed in patients unable to tolerate warfarin therapy and/or who are unable to obtain satisfactory INR control despite specific measures. This would require a definition of "satisfactory INR control" together with potential price-volume arrangements that address the risk to the Australian Government of use beyond such restrictions

This recommendation has resulted in PBAC undertaking further analysis as it reviews its previous decisions (NPS MEDICINEWISE, 2012).

\section{PROPOSED MODEL AND ASSOCIATED ACTIVITIES}

Figure 1 outlines the suggested new model to better manage the entry of new drugs in the future. This is based on the extensive knowledge and experience of the co-authors shared across healthcare institutions. This builds on the three pillars of pre, peri-, and post-launch activities (Wettermark et al., 2010a; Godman et al., 2012d).

This starts with horizon scanning activities pre-launch and continues to post-launch monitoring, benchmarking, and registries. Potential activities for each stakeholder group are discussed later in Table 4.

There has been a growth in risk sharing arrangements across Europe as health authorities and health insurance companies struggle to fund new premium priced products within available funds (Adamski et al., 2010; Godman, 2011; Jaroslawski and Toumi, 2011; Klemp and Frønsdal, 2011; Cheema et al., 2012; Hirschler, 2012; Jommi, 2012; Siviero et al., 2012; Vogler et al., 2012). Risk sharing has previously been defined as agreements concluded by payers and pharmaceutical companies to diminish the impact on the payer's budget of new and existing medicines brought about by either the uncertainty of the value of the medicine and/or the need to work within finite budgets (Adamski etal., 2010; Godman, 2011). Consequently, the agreement lies in setting the scope and realizing the mutual obligations amongst both payers and pharmaceutical companies depending on the occurrence of an agreed condition the "risk," which varies by situation (Adamski etal., 2010; Godman, 2011).

In view of the concerns with some of these schemes, coupled with the experiences with dabigatran across Europe (Table $\mathbf{1}$ and Table A1 in the Appendix), national and regional health authorities and health insurance companies should consider a number of key issues when appraising risk sharing schemes in the future (Table 2). These considerations do not apply to price:volume agreements, straight discounts or rebates, which are easier to administer (Jaroslawski and Toumi, 2011).

Health authorities and health insurance companies also need to consider a number of key issues before implementing patient registries. Key considerations and issues are shown in Table 3. Patient registries can subsequently be used to assess the effectiveness, safety and cost-effectiveness of new treatments in routine clinical care. The nature and extent of data collected will depend on the objectives of any study.

Overall, there are a number of activities that each key stakeholder group should consider pre-, peri-, and post-launch to better manage the entry of new drugs. This is especially important where there are potential safety and/or resource issues (Table 4). These build on the three pillars and a brief outline of activities discussed in Figure 1.

\section{EMA AND FDA ACTIVITIES}

The low mean bioavailability of dabigatran (Douxfils et al., 2012; Mannuci et al., 2012; Ten Cate, 2012), as well as studies demonstrating considerable variation in plasma drug concentrations in practice, led the FDA in 2010 to explore the relationship between dabigatran concentrations in plasma and the risks of suffering a stroke or major bleeding (Thompson, 2010; Ten 
Table 1 | Summary of key activities across Europe to improve the quality and efficiency of prescribing of dabigatran (Godman et al., 2008, 2009a,c, 2011a, 2012d; Holmström et al., 2009; Janusinfo, 2009, 2012a,b; KVH - Aktuell, 2010; Martikainen et al., 2010; Wettermark et al., 2010a,c; Boehringer Ingelheim, 2011 b; Gustafsson et al., 2011; Neue Arzneimittel, 2011; Stockholms läns landsting, 2011; Vončina et al., 2011; Keele University School of Pharmacy, 2012; Medicin \& Läkemedel, 2012; Midlands Therapeutic Review and Advisory Committee [MTRAC], 2012; Östergötland, 2012; Persson et al., 2012; Davidson et al., 2013).

\section{Timing Examples of activities among European countries and regions}

Pre-launch Swedish counties:

(principally $\quad$ (A) Östergötland County Council

education) - Update of the previous report on the prevalence of atrial fibrillation in Östergötland

- Establishing a working party with broad representation from the departments of cardiology and internal medicine, primary health care, representatives from the warfarin polyclinics, epidemiologist and health economists associated with the Drug and Therapeutics Committee (DTC)

- Scientific publication of the cost-effectiveness model for dabigatran for the prevention of stroke based on Östergötland by the Centre for Medical Technology Assessment, Linköping University, in collaboration with Östergötland County Council

- Consensus action plan agreed 12 months before dabigatran was registered for the prevention of stroke in patients with AF

- Recommendation from the DTC to classify dabigatran as a "focus-drug", i.e., the prescribing unit will be responsible for the cost of the drug. If however patients are entered into the County Council's quality assessment program, the cost will be borne by the County Council. Decision by the County Council to follow the recommendation of the DTC

- Resources for treating patients allocated in the 2011-2012 County Council drug budgets

- Communication plan implemented

(B) Stockholm County Council

- Systematic and long-term involvement of medical and scientific expertise in the development of guidelines and advise to patients and prescribers through the Regional Drugs and Therapeutic Committee (DTC) and clinical pharmacologists

- Extensive pre-launch activities with key messages broadcasted both to the public and to prescribers through websites of the DTC as well as the Swedish Medical Journal

- Appreciable number of pre-launch meetings and training sessions with all major physician groups around the key issues and concerns with dabigatran as well as its likely place in care

- Production of educational folders regarding dabigatran, slide kits, published articles, and data on the Janus website as well as published information for patients

- Forecasting the potential budget impact in 2011 and 2012 ahead of launch and monitoring this in practice

- Development of a laboratory method to monitor dabigatran in plasma with LC-MS/MS technology, and recommending sampling in the introductory phase to build a knowledge database. This to be followed by more situation-based sampling to improve patient safety in the future

\section{Peri-launch (A) West Midlands (Region - England)}

(principally - Development of guidance stating that warfarin remains the first-line option for anticoagulation in patients with AF at high risk of a stroke, education) and primary care trusts (have been replaced by Clinical Commissioning Groups from April 1, 2013) should ensure optimal existing warfarin therapy services - including access to INR clinics, use of computerized decision-support software, and access to drugs for patients who are allergic to warfarin (the latter rare in practice)

- In addition in view of the considerable financial implications, dabigatran treatment should only be prescribed for patients:

- with co-morbidities who are adherent to warfarin monitoring and lifestyle requirements but need frequent co-prescribed medications that interact with warfarin and affect the patients' time in the therapeutic range (TTR)

- who are adherent to monitoring and lifestyle requirements but whose TTR remains unacceptable despite attempts to optimize treatment with warfarin (TTR rates should be set locally)

(B) Germany

- Physician Associations stressing when launched that the current knowledge regarding safety with dabigatran was insufficient to answer all questions, and physicians should be careful with prescribing particularly in the elderly

- The reporting of deaths from excessive bleeding further endorsed these concerns. As a result, limited prescribing in practice in ambulatory care

(C) Slovenia

- Reimbursed in conjunction with a complex price:volume agreement 


\section{Table 1 | Continued}

\section{Timing Examples of activities among European countries and regions}

Post-launch (A) Austria (enforcement)

(principally - Ex ex-ante approval by the head physician of the patient's social health insurance fund before reimbursement of dabigatran; otherwise education $\quad 100 \%$ co-payment (mirroring other situations)

and enforce- $\quad$ - Renal function has to be assessed and recorded prior to initiation of therapy with dabigatran through determining Creatinine-Clearance ment) $(\mathrm{CrCl})$ levels to exclude patients with severe renal dysfunction ( $=\mathrm{CrCl}<30 \mathrm{ml} / \mathrm{min}$ ). In addition during treatment, renal function has to be monitored where a decline is envisaged, e.g., patients with hypovolemia, dehydration, and the use of specific additional medication, and renal function has to be assessed at least once a year in patients aged 75 or older, and/or in patients with compromised renal function

(B) Finland (enforcement)

- Reimbursement restricted to patients with risk factors where satisfactory control has not been reached with warfarin; alternatively, warfarin cannot be prescribed due to side-effects or contra-indications

- Enforcement at the pharmacy with on average 16 days needed for requests to be centrally reviewed and authorized. Hundred percent co-pay without authorization

(C) Slovenia

- Education of all involved specialists and primary care physicians on key safety aspects/adverse events with dabigatran

- Prescribing restrictions (Enforcement):

- Only reimbursed if initiated by an internist or neurologist and prescribed according to agreed indications, e.g., only reimbursed in patients already on warfarin if they are unstable with TTR $<65$

- Patients have to be followed in a tertiary or secondary care anticoagulation center. Patients can be followed in primary care but only if authorized by the tertiary or secondary care center.

- Every patient has to be registered in a database and followed by the IT anticoagulation program

- Anticoagulation centers have to report once yearly to the tertiary center regarding the number of patients experiencing minor and major bleeding, thromboembolic events, as well as any deaths from bleeding or thromboembolism with dabigatran

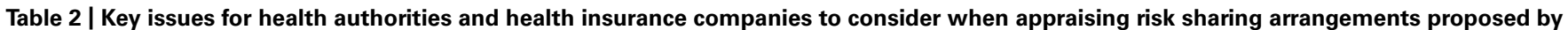
pharmaceutical companies for new drugs.

\section{Key issues regarding risk sharing arrangements}

- Validity of the appropriateness of the arrangement(s) for the situation/circumstances in the country/region incorporating current or proposed service delivery arrangements and involving the use of experts

- Specificity and transparency of the objectives and scope of the proposed scheme(s)

- Novelty of the new drug - including its envisaged health gain, assessment of the effectiveness of current treatments, priority of the disease area, and the translational evidence base

- Proportion health authorities will end up funding of a new drug's development costs through registries post-launch

- Data ownership - ideally, all key stakeholders should be involved in the development of any subsequent patient registries. In principal, these should be funded by the manufacturer

- Feasibility of IT infrastructure already in place to collect data to monitor the agreement(s) in practice. Alternatively, if new structures are needed, their development costs need to be considered alongside the financial benefits of any proposed risk sharing scheme

- Beneficial impact on service delivery and/or safety of the new drug. This should be substantial but has been difficult to prove in Phase III trials

- Administrative burden of any proposed risk sharing scheme in relation to the potential overall savings

- Likely patient concordance in practice, especially if this has not been fully considered in the proposed scheme(s) 


\section{Time lines Pre- and Peri- Launch}

\section{2-3 years before likely EMA authorisation}

1 year from EMA authorisation
EMA authorization
Reimbursement (National and Regional)
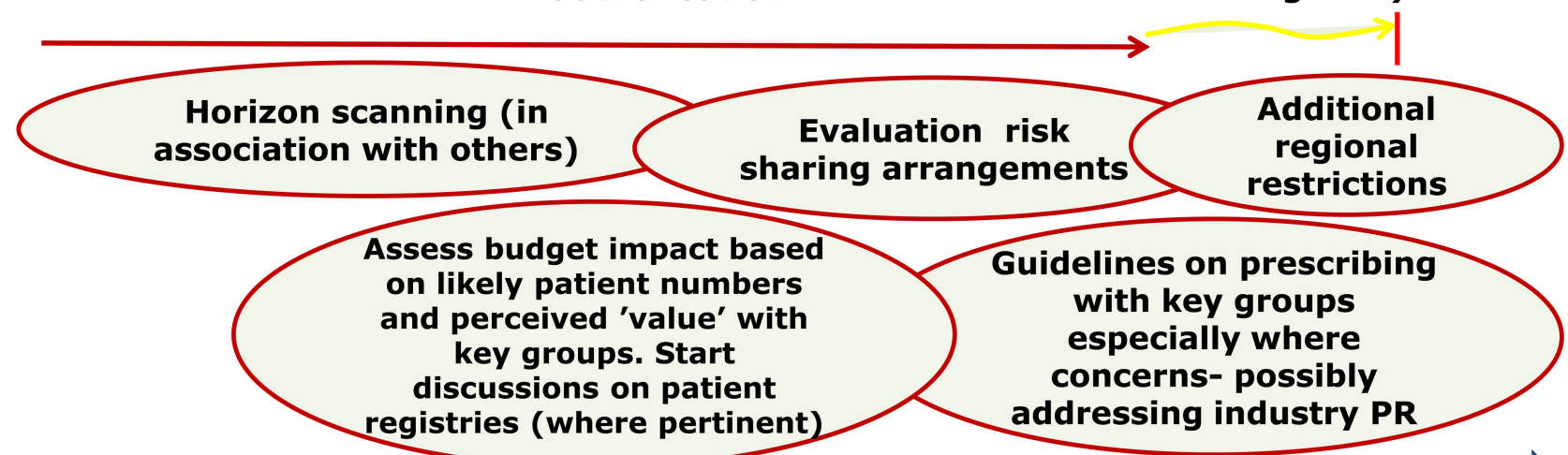

Peri and post-launch activities

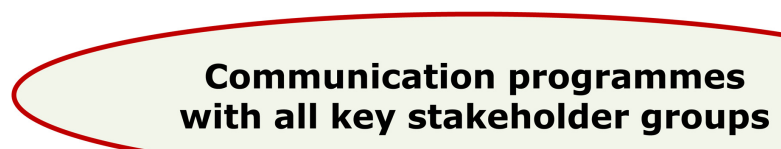

\section{Patient follow-up on} effectiveness and safety in practice using registries or Electronic Health Records

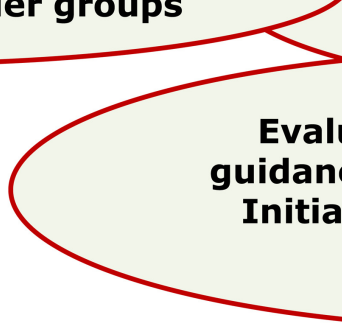

Evaluate adherence to agreed guidance/ guidelines/ restrictions.

Initiate additional demand-side measures if needed

FIGURE 1 | Proposed model for optimizing the managed entry of new drugs across Europe incorporating national and regional stakeholder groups where pertinent building on the example of dabigatran.

Cate, 2012). These publications also demonstrated it is important to avoid too low or too high levels of dabigatran (Mismetti and Laporte, 2010; Thompson, 2010). Consequently similar to warfarin, certain patients on dabigatran and other NOACs should be monitored to reduce potential side-effects (Mismetti and Laporte, 2010; Douxfils etal., 2012; Mannuci et al., 2012; Ten Cate, 2012).

The EMA in their Risk Minimization Plan for dabigatran issued in 2011 also defined a cut-off for the risk of bleeding with the $150 \mathrm{mg}$ bid regimen of $200 \mathrm{ng} / \mathrm{mL}$ dabigatran in plasma at $\mathrm{C}_{\text {trough }}$ (Heidbüchel et al., 2011).

\section{DISCUSSION}

Dabigatran and the other NOACs are the result of a long search for an alternative to warfarin to prevent strokes in patients with AF. However, the weighing of the advantages and disadvantages associated with dabigatran, especially in the elderly with poor renal function, needs to be judged carefully and handled appropriately alongside the additional acquisition costs of dabigatran. These challenges led to an extensive range of activities among national and regional health authorities, health insurance companies, and physician associations across Europe pre-, peri-, and post-launch to enhance its appropriate use (Table $\mathbf{1}$ and Table A1 in the Appendix).

The main medical concerns were the risk of excessive bleeding in elderly patients with AF with no known antidote, variable plasma drug concentrations in practice exacerbated by low bioavailability, and the dependence on renal elimination of the active metabolite (Baetz and Spinler, 2008; Malmström, 2009; Legrand et al., 2011; Liesenfeld et al., 2011; Banerjee et al., 2012; Douxfils et al., 2012; Godman et al., 2012d; Harper et al., 2012; Huisman et al., 2012; Mannuci et al., 2012; Ten Cate, 2012; Marshall et al., 2013). Cases of major bleeding and deaths were seen with dabigatran soon after its launch (Malmström, 2009; Institute for Safe Medication Practices, 2011; EMA, 2011; Legrand et al., 2011; Wood, 2011; Garber et al., 2012; Godman et al., 2012d; Harper et al., 2012; Mannuci et al., 2012; Lothian Prescribing Bulletin, 2012; Marshall et al., 2013). The EMA reported on November 
Table 3 | Key issues for authorities to consider when planning patient registries post-launch.

\section{Events/timing Key considerations regarding patient registries}

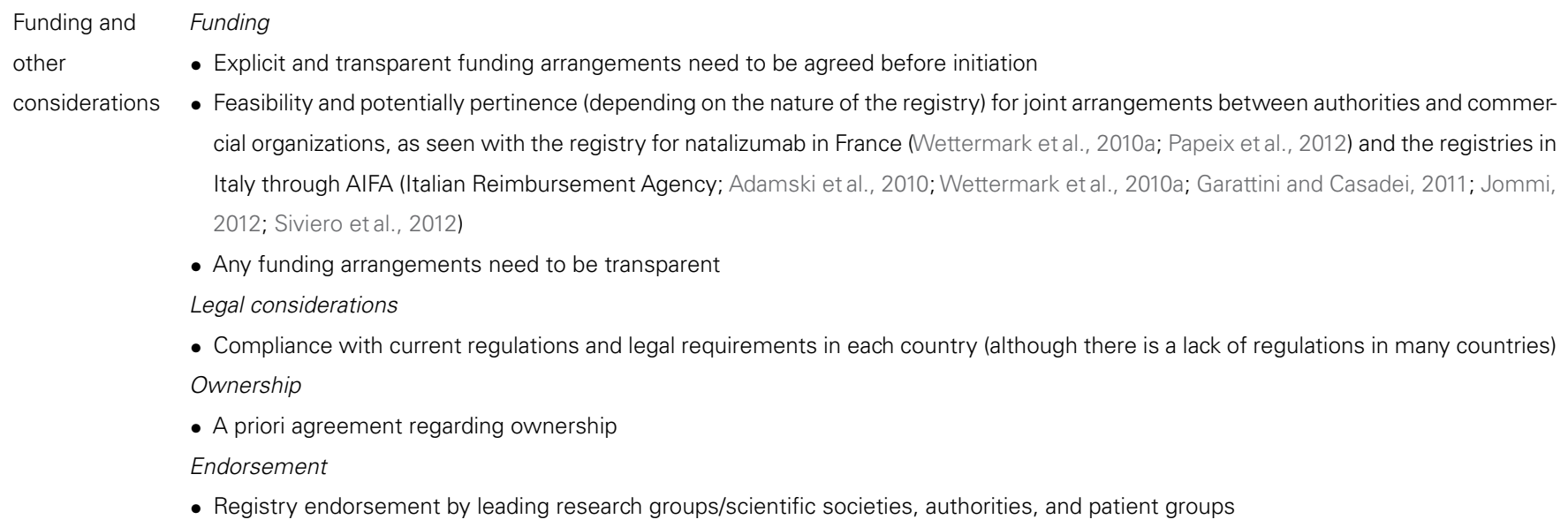

Timing - Timelines: ensure sufficient time is made available to develop "user friendly" registries that will fully capture all the patient variables of interest and which satisfy the interests of all key stakeholder groups as compromise will be inevitable. This includes:

- Ensuring as far as possible ease of use and acceptability of effort of all those involved

- Ensuring the competence of those entering the data at every data entry point, especially with key issues such as adverse events; enhanced if patients are already experiencing difficulties with their condition such as depression, sleep disorders, fatigue and mobility, as seen in patients with multiple sclerosis. It helps if the disease area is the specialty of those entering the data

- Data functionality of patient registries need to be considered early pre-launch (Figure 1), and time given to recruit personnel competent in computer science and knowledgeable in the major medical issues for the disease area. This will facilitate the development of user friendly screens and data entry to enhance the completeness and accuracy of data entry. In addition, incorporate systems that help detect errors quickly regarding data entry, e.g., trigger tools

6, 2011 that there had already been 256 spontaneous reports of serious bleeding resulting in deaths in the EudraVigilance database (EMA, 2011).

Table 1 and Table A1 in the Appendix document the extensive range of activities initiated across Europe. These include educational activities pre-launch in Stockholm County Council, Sweden, as well as post-launch activities among regions and localities in Germany, Spain, Sweden, and the UK. There were also prescribing restrictions in some countries alongside the development of shared care protocols between ambulatory and hospital care to improve interface management and enhance the subsequent quality of care (Godman et al., 2012e). It is suggested that these activities reduced subsequent bleeding among patients in practice, especially among those with poor renal function and, as a result, potentially helped preserve the availability of dabigatran across Europe. This is unlike that situation seen with a number of drugs described earlier including zimelidine, COX-II inhibitor drugs, cerivastatin, and rimonabant (Fagius et al., 1985; Carlson, 1999, 2000; Friedman et al., 1999; FDA, 2002; Merck, 2002, 2004; MHRA UK, 2004; Calfee and Pinell, 2005; European Medicines Agency [EMA], 2009; Moreira et al., 2009; O'Shaughnessy, 2009; Eichler et al., 2011; Ioannides-Demos et al., 2011; Kappos et al., 2011; Keegan, 2011; Dietrich and Horvath, 2012). However, it is difficult to substantiate this without definite research. Having said this, reimbursement of dabigatran has recently been rejected in Poland due to concerns with excessive bleeding and deaths (Table A1 in the Appendix).

There have also been issues with the additional costs of dabigatran versus warfarin at GB£919.80 (€1060) per patient (UK) given the growing prevalence of AF with currently over 4.5-6 million patients across Europe and rising (Lloyd-Jones et al., 2004; Stewart et al., 2004; Camm et al., 2010; Pink et al., 2011; Mannuci et al., 2012; Marshall et al., 2013). However, there is less of a budget differential in Sweden (Davidson et al., 2013). These combined issues led to (i) prescribing restrictions in some countries alongside prior authorization schemes, e.g., Austria, Belgium, Finland, NHS Bury (initially), Slovakia, and Slovenia, (ii) delays with reimbursement in others including Croatia (still undergoing review), the Netherlands, Norway (only just reimbursed), and Portugal (150 mg); as well as (iii) price:volume and other agreements (risk sharing) to lower the price of dabigatran, e.g., Ireland, the Netherlands, and Slovenia as well as potentially in Croatia (Table $\mathbf{1}$ and Table A1 in the Appendix). These concerns have also resulted in dabigatran not being reimbursed/not preferred as an alternative in some countries and regions including Estonia, Lithuania, Lothian Health Board (Scotland), NHS Cornwall Community Health, the Republic of Serbia, and Turkey (Table A1 in the Appendix). Prescribing restrictions and risk sharing arrangements are no 
Table 4 | Key considerations among stakeholder groups to optimize the managed entry of new drugs (Garattini et al., 2008; Godman et al., 2008,

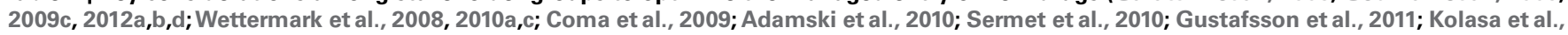
2011; Vončina et al., 2011; Cheema et al., 2012; Siviero et al., 2012; Godman and Gustafsson, 2013).

\section{Stakeholder}

Health authorities/

health insurance

companies/

physician

associations

\section{Key considerations among stakeholder groups to optimize the managed entry of new drugs}

Pre-launch

- Plan early for the launch of new drugs especially those that could have an appreciable budget impact and/or safety considerations. This can be through working with countries/regions already engaged in such activities

- Work alongside key multi-professional groups including independent pharmacotherapeutic experts such as general practitioners, pharmacists, and clinical pharmacology groups. This will help with critically appraising the potential role and value of new treatments ahead of their launch, as well as with developing robust budget impact models for future forecasts. Where possible, Drug and Therapeutic Committees (DTCs) and expert groups should have a major role to ensure consistent priorities for recommendations across divergent pharmacotherapeutic groups

- Work with regulators to:

- Review potential areas of concern with new treatments, especially around safety issues and potential ways to address this

- Check information provided by commercial organizations is comprehensive, addressing any potential publication bias (Melander etal., 2003; Kirsch etal., 2008; Martin, 2012). The need for this should reduce with ongoing activities among pharmaceutical companies to fully disclose trial data (Kmietowicz, 2013)

- Plan early for the:

- Incorporation of any pharmacogenetic tests that should to be available when a new "valued" drug is launched to enhance its appropriate use

- Development of any patient registries to assess the effectiveness/safety of new drugs in practice (pharmacovigilance) as well as monitor prescribing against agreed guidance (Table $\mathbf{3}$ )

- Any necessary re-designing of services, e.g., anticoagulation services with the launch of new anticoagulants

- Regularly assess which products will lose their patent in the coming 1-2 years to help fund new premium priced drugs in the disease area/related disease area - especially with growing resource pressures. These activities will assist financial planning generally

- Work with pertinent patient groups especially regarding new treatments that could have serious patient issues to help instigate appropriate educational campaigns for physicians and patients pre- to post-launch. Similarly also with key physicians, including those within DTCs, to develop suitable educational and communication materials including guidelines for physicians

Peri-launch

- Consider the development of any potential new quality or prescribing indicators together with key stakeholder groups within and across European countries. This includes their assessment in practice, acknowledging that any indicators developed must have content validity, face validity, concurrent validity, construct validity and predictive validity

- Include any indicators developed in new guidance/guidelines and, if appropriate, within ongoing financial incentive schemes for physicians to optimize the use of new premium priced drugs at launch

- Be critical of any proposed risk sharing arrangements using the criteria summarized in Table 2 - mindful that such arrangements post-launch could facilitate reimbursement and funding of new premium priced drugs (Table A1 in the Appendix-e.g., Netherlands and Slovenia)

- Continually check likely launch dates for new treatments with pertinent pharmaceutical companies to improve financial planning

Post-launch

- Use administrative and/or medical databases to compare "real world" patients with those included in Phase III RCTs in terms of their clinical features, treatments, and potential outcomes to further refine prescribing guidance and/or reimbursed prices especially if greater co-morbidity in "real world" patients (Joppi et al., 2013)

- Build in regular reviews of any reimbursement/funding/guidance especially as more data becomes available, e.g., more recent data challenging "no patient monitoring" with dabigatran especially if "no patient monitoring" was built into submitted economic analyses

- Monitor physician adherence to any agreed guidance/reimbursement restrictions and potentially instigate academic detailing and other activities where continued concerns with prescribing 


\section{Table 4 | Continued}

\section{Stakeholder Key considerations among stakeholder groups to optimize the managed entry of new drugs}

Physicians Peri-launch

- Work with health authorities and health insurance companies pre-launch to critically review new treatments, especially where there are concerns with patient safety, to help enhance their appropriate use at launch and their retention on the market

- Provide guidance to health authorities and health insurance companies regarding optimal patient populations that maximize the value of new drugs, as well as potential quality/prescribing indicators

- Provide input into discussions on the potential value of pertinent pharmacogenetic tests that may help optimize the use of new drugs post-launch

- Help with the development of educational materials for physicians and patients peri- and post-launch including the development of any clinical guidelines based on agreed guidance

- Assist with the design of any patient registries prior to launch, and follow this up after launch (Table 3). This can also include programs that measure drug sequencing against any agreed guidance

- Help authorities critically assess proposed risk sharing arrangements, especially regarding the administrative burden and other key issues (Table 2)

- Assist hospital and ambulatory care DTCs with critically evaluating new treatments, as well as with the planning of any interface arrangements to improve the co-ordination of care between primary and secondary care physicians post launch

Post-launch

- Provide input into any patient registries (Table 3) to help assess the true value of the new drug especially where there are concerns with safety in a wider co-morbid population post launch than those enrolled into Phase II and III trials

- Provide input when clinical guidelines are revised as more data becomes available

\section{Patient Pre-launch}

organizations - Provide input to health authorities and health insurance companies pre-launch regarding any safety and effectiveness issues for new drugs from the patients' perspectives

- This includes any pertinent pharmacogenetic tests that help optimize the use of new drugs to patient populations where the benefit:risk ratio (and hence "value") is maximized

Pre- and peri-launch

- Provide input into the design and distribution of any patient information regarding new drugs, especially where potential safety issues, pre- and peri-launch

- Provide input into the design of any quality/prescribing indicators for new drugs especially where there are issues of safety and sequencing as well as where compliance is likely to be a concern

Post-launch

- Help further refine information for patients as more knowledge becomes available about the new drug, especially regarding key side-effects and their implications

- Help disseminate factual information to patients if pertinent, especially where there are exaggerated claims unduly raising expectations among patients or where issues of side-effects have not been adequately disseminated

\section{Commercial Pre-launch}

organizations - Interact early with pertinent health authorities and health insurance companies, especially for new premium priced drugs, to review key comparator and outcome data to include in Phase II/III clinical trials. Comparator and outcome data will depend on the disease area and target prices. Included in this should be discussions regarding resource issues and budget impact at launch to aid planning, acknowledging the particular characteristics of each market

- This may include discussions on study design with increasing knowledge of pharmacogenomics and the implications for subsequent trial designs with potentially smaller populations (this will be explored further in future papers) 


\section{Stakeholder Key considerations among stakeholder groups to optimize the managed entry of new drugs}

- Provide health authorities and health insurance companies with all relevant data in a timely fashion pre-launch, rather than selective data, to aid decision making and reduce scepticism. This is important to address current concerns that manufacturers are still hiding/not providing data that potentially reduces the value of their product (Martin, 2012); although some companies are now addressing this (Kmietowicz, 2013)

- Relevant data includes key adverse event data or pharmacokinetic data - especially if there are concerns about potential claims in practice as seen with concerns with the "no requirement for patient monitoring" with dabigatran

- Be pragmatic when planning target prices taking into account key decision making criteria for the pertinent country or region, including either cost/QALY considerations or clinical data requirements for new drugs to be seen as innovative or adding clinical value. This includes any discounts or rebates as part of any risk sharing arrangements (Table 2), acknowledging that the majority of new drugs are seen as similar by payers, with only a minority seen after critical evaluation to have added patient benefits compared with existing standards. These considerations have grown in importance with ongoing resource pressures, i.e., mindful of opportunity cost considerations within health authorities and health insurance companies

Peri- and post-launch

- Resist the urge to over promote new drugs especially to the public where there are safety issues, thereby reducing the potential for further restrictions/early withdrawal

- Potentially monitor and refine risk sharing arrangements as more data becomes available

doubt preferred by manufacturers versus not having their drugs reimbursed.

The weighing up of the benefits and concerns with dabigatran make it increasingly important for European countries and regions to develop and refine models to further improve the managed entry of new premium priced drugs, even if they do not have a tradition of Health Technology Assessment (HTA). The alternative could be reduced resources to fund new drugs in the future, especially with a growing elderly population, which is already happening (Garuoliene et al., 2011a,b; Godman et al., 2011c, 2012b; Taylor, 2011). As mentioned previously, budgetary pressures are growing as a result of the number of new biological drugs in development (EvaluatePharma, 2012; Godman, 2013) including new cancer drugs (Nagle et al., 2008; National Cancer Institute, 2010; Sullivan et al., 2011; Mullard, 2012), which are now costing up to US $\$ 10,000-25,000$ (€7580-18,960) per patient per month (Selyukh, 2011; Yukhananov, 2011; Kaiser, 2012; UK Medicines Information, 2012; UKMi Medicines Information, 2013). Such models may also reduce the possibility of new drugs such as dabigatran being withdrawn from the market due to a greater level of side-effects in a wider co-morbid population than that included in the clinical trials (Joppi et al., 2013). None of these alternative scenarios are in the best interests of any key stakeholder group.

Moreover, it is critical that health authorities and health insurance companies take full advantage of the increasing availability of standard drugs as generics to help fund increased volumes and new premium priced drugs in the future (Frank, 2007; Jack, 2008; Godman et al., 2012a,b,f). For example, expenditure on proton pump inhibitors (PPIs) and statins would have been GB£449 million ( $€ 520$ million) higher in Scotland in 2010 without appreciable demand-side measures enhancing the prescribing of low cost generics for its 5.2 million population (Bennie et al., 2012; Godman et al., 2012b). This activity is driven by global sales of products likely to lose their patents between 2008 and 2013 estimated at US\$50-100bn (€38-76bn), and considerably higher for subsequent years (Frank, 2007; Jack, 2008; Godman et al., 2012b,f), out of global sales of pharmaceuticals estimated at US\$820bn (€625bn) in 2009 (EATG, 2009).

The next stage of our research will be to assess the influence of the plethora of health authority and health insurance company activities (Table $\mathbf{1}$ and Table A1 in the Appendix) on subsequent utilization of dabigatran and other NOACs, alongside ongoing reforms, to further refine the suggested model (Figure 1). This should also help with future recommendations regarding potential demand-side measures that could be introduced to further improve the managed entry of new drugs, based around the four Es (Wettermark et al., 2009a). This includes the implications for all key stakeholder groups (Table 4). We are already seeing health authorities and health insurance companies monitor the effectiveness and safety of patients prescribed dabigatran and other NOACs, and this will grow.

In the meantime, we hope we have demonstrated why it is imperative that health authorities and health insurance companies continue to develop and refine new models to better manage the entry of new drugs in the future. In addition, we hope we have provided direction to all key stakeholder groups based on our considerable experience to further stimulate this debate in this critically important area. This especially as the constant introduction of new premium priced drugs is seen as the greatest challenge to the continued provision of equitable and comprehensive healthcare in Europe (Garattini et al., 2008; Godman et al., 2012d). 


\section{CONCLUSION}

There have been multiple activities pre- to post-launch among authorities across Europe to improve the prescribing of dabigatran, especially in elderly patients where there are concerns with their renal function. In addition, address potential concerns with the budget impact of dabigatran through for instance price:volume agreements and prescribing restrictions.

We believe and recommend, based on the experiences with dabigatran and other new premium priced drugs, that it is essential for authorities to develop new models to better manage the entry of new drugs in the future (Figure 1). This is becoming critical given the number of new premium priced drugs in development.

Critical activities for health authorities and health insurance agencies pre-launch in the future involve horizon scanning and budget planning activities. This includes identifying products likely to lose their patent within the next 1-2 years. In addition, educational materials and clinical guidance need to be developed pre-launch with the help of physicians and patient groups. Key peri-launch activities include developing prescribing indicators for new treatments as well as the critical appraisal of any proposed risk sharing arrangements, assessed against the criteria documented in Table 2 . Essential post-launch activities include monitoring of prescribing against agreed guidance. Increasingly also entering patients into registries to monitor the effectiveness and safety of new drugs in wider patient populations having considered key issues (Table 3).

Without such models, authorities may well struggle to maintain the European ideals of equitable and comprehensive healthcare as well as ensuring funding for new "valued" treatments in target populations. Consequently, the development of new models to better manage the entry of new drugs should be in the interest of all key stakeholder groups.

\section{ACKNOWLEDGMENTS}

This work was in part supported by grants from the Karolinska Institutet, Sweden. The authors would like to thank Elina Asola and Jaan Martikainen from Finland for their help with the data from Finland and critiquing previous drafts. No writing assistance was provided for this paper.

\section{REFERENCES}

Abraham, J. (2008). Sociology of pharmaceuticals development and regulation: a realist empirical research programme. Sociol. Health Illn. 30, 869-885.

Adamski, J., Godman, B., OfierskaSujkowska, G., Osinska, B., Herholz, H., Wendykowska, K., et al. (2010). Review of risk sharing schemes for pharmaceuticals: considerations, critical evaluation and recommendations for European payers. BMC Health Serv. Res. 10:153. doi: 10.1186/1472-6963-10-153

\section{AUTHOR CONTRIBUTIONS}

All authors critiqued successive drafts to develop robust recommendations. Additional specific areas include: Brian B. Godman - developed the first draft and co-ordinated activities and inputs regarding additional drafts; Rickard E. Malmström, Eduard Diogene, Christoph Baumgärtel, and Lars L. Gustafsson - provided input regarding dabigatran and NOACs, as well as comments regarding patient registries, clinical trial design and physician activities; Marion Bennie, Iain Bishop, and Jan Jones - provided data regarding Scotland. Jan Jones also critiqued the health economic section particularly regarding SMC; Anna Brzezinska, Kamila Malinowska, and Magdalena Wladysiuk - provided data regarding Poland; Anna Bucsics and Jutta Piessnegger provided data regarding Austria; Stephen Campbell - provided specific input regarding the development of quality indicators along with Menno van Woerkom; Alessandra Ferrario and Alexander Finlayson - critiqued successive drafts using their expertise in health services research across a range of countries; Jurij Fürst provided data on Slovenia; Kristina Garuoliene - provided data on Lithuania; Miguel Gomes - provided data on Portugal; Iñaki Gutiérrez-Ibarluzea, Eduard Diogene, and Corrine Zara - provided data on the Spanish regions; Iñaki Gutiérrez-Ibarluzea, Alan Haycox, Laura McCullagh, Ken Paterson, and Magdalena Wladysiuk-provided guidance regarding the health economic data; Alan Haycox, Julie Lonsdale, Andrew Martin, and Michael Wilcock provided data on England. Krystyna Hviding and Christina Kvalheim - provided data on Norway; Harald Herholz, Irene Langner, and Gisbert Selke - provided data on Germany; Mikael Hoffmann, Lars L. Gustafsson, Rickard E. Malmström, and Sven-Åke Lööv provided data on county council activities in Sweden; Saira Jan provided data regarding post launch activities in the US; Roberta Joppi - provided data on Italy as well as data on the characteristics of patients with AF compared to the clinical trial populations; Marija Kalaba - provided data on the Republic of Serbia; Ott Laius - provided data on Estonia; Laura McCullagh - provided data on Ireland; Vanda Markovic-Pekovic - provided data on the Republic of Srpska; Catherine Sermet - provided data on France; Steven Simoens - provided data on Belgium; Cankat Tulunay provided data on Turkey; Dominik Tomek - provided data on Slovakia; Luka Vončina and Vera Vlahovic-Palcevski - provided data on Croatia; Janet Wale - critiqued comments regarding potential patient involvement in new models; Menno van Woerkom - also provided data on the Netherlands.

atrial-fibrillation-files/reportanticoagulation.pdf (accessed January 2013).

Baetz, B. E., and Spinler, S. A. (2008). Dabigatran etexilate: an oral direct thrombin inhibitor for prophylaxis and treatment of thromboembolic diseases. Pharmacotherapy 28, 1354 1373.

Banerjee, A., Lane, D. A., TorpPedersen, C., and Lip, G. Y. (2012). Net clinical benefit of new oral anticoagulants (dabigatran, rivaroxaban, apixaban) versus no treatment in a 'real world' atrial fibrillation population: a modelling analysis based on a nationwide cohort study. Thromb. Haemost. 107, 584-589.

Baumgärtel, C., Godman, B., Malmstrom, R. E., Andersen, M., Abuelkhair, M., Abdu, S., et al. (2012). What lessons can be learned from the launch of generic clopidogrel? GaBi J. 1, 58-68.

Bennie, M., Godman, B., Bishop, I., and Campbell, S. (2012). Multiple initiatives continue to enhance the prescribing efficiency for the proton pump inhibitors 
and statins in Scotland. Expert Rev. Pharmacoecon. Outcomes Res. 12, 125-130.

Boehringer Ingelheim. (2011a) Breakthrough Therapy PRADAXA ${ }^{\circledR}$ (Dabigatran Etexilate) First Drug in 50 Years to Gain Approval for Stroke Prevention in Atrial Fibrillation in EU. Available at: http://www.boehringeringelheim.com/news/news_releases/ press_releases/2011/04_aug_2011_ dabigatranetexilate.html (accessed December 2012).

Boehringer Ingelheim. (2011b). Mitteilung an die Angehörigen der Heilberufe zur Bedeutung einer Überprüfung der Nierenfunktion von Patienten, die mit Pradaxa ${ }^{\circledR}$ (Dabigatranetexilat) behandelt warden. Available at: http://www. akdae.de/Arzneimittelsicherheit/ RHB/Archiv/2011/20111027.pdf (accessed December 2012).

Bombardier, L., Laine, L., Reicin, A., Shapiro, D., Burgos-Vargas, R., Davis, B., et al. (2000). Comparison of upper gastrointestinal toxicity of rofecoxib and naproxen in patients with rheumatoid arthritis. N. Engl. J. Med. 343, 1520-1528.

Bresalier, R., Sandler, R., Quan, H. Bolognese, J. A., Oxenius, B., Horgan, K., et al. (2005). Cardiovascular events associated with rofecoxib in a colorectal adenoma chemoprevention trial. N. Engl. J. Med. 352, 1092-1102.

Burke, P. (2012). Communications (by letter) from Mr. P. Burke (Primary Care Reimbursement Services, Health Services Executive, Ireland) to All Chairpersons/Secretaries of Drug and Therapeutic (Pharmacy and Therapeutic) Committees, Consultant (Cardiologists, Geriatricians, Haematologists, Neurologists, Stroke Physicians), Hospital Chief Pharmacists, Ireland, July 2012.

Calfee, J. E., and Pinell, X. (2005). Prepared for a Conference on Consumers, Information, and the Evolving Healthcare Market Place. Available at: http://www.aei.org/papers/health/thesignificance-of-the-vioxx-

withdrawal/ (accessed December 2012).

Camm, A. J., Kirchhof, P., Lip, G. Y., Schotten, U., Savelieva, I., Ernst, S., et al. (2010). ESC Guidelines for the management of atrial fibrillation the task force for the management of atrial fibrillation of the European Society of Cardiology (ESC). Eur. Heart J. 31, 23692429.

Carlson, A. (1999). "The discovery of SSRIs: a milestone in neuropsychopharmacology and rational drug design," in Selective Serotonin Reuptake Inhibitors: Past, Present and Future, ed. S. C. Standford (Austin: R.G. Landes Company), 1-7. Available at: http:// elib.fk.uwks.ac.id/asset/archieve/ebook/FISIOLOGI\%20-\%20FAAL \%20-\%20PHISIOLOGY\%20$\% 20$ PATHOFISIOLOGY/Selective $\% 20$ Serotonin\%20Reuptake\%20 Inhibitors.pdf (accessed January 2013).

Carlson, A. (2000). A half century of neurotransmitter research; impact on neurology and psychiatry. Nobel lecture December 2000. Available at: http://www.nobelprize.org/ nobel_prizes/medicine/laureates/ 2000/carlsson-lecture.pdf (accessed January 20123)

Cheema, P., Gauvra, S., Migus, M., Godman, B., Yeung, L., Trudeau, M. E., et al. (2012). International variability in the reimbursement of cancer drugs by publically funded drug programs. Curr. Oncol. 19, e165-e176.

Civaner, M. (2012). Sale strategies of pharmaceutical companies in a 'pharmerging' country: the problems will not improve if the gaps remain. Health Policy 106, 225-232.

Coma, A., Zara, C., Godman, B., Augusti, A., Diogene, E., Wettermark, B., et al. (2009). Policies to enhance the efficiency of prescribing in the Spanish Catalan Region: impact and future direction. Expert Rev. Pharmacoecon. Outcomes Res. 9, 569-581.

Connolly, S. J., Ezekowitzs, M. D., Yusuf, S., Eikelboom, J., Oldgren, J., Parekh, A., etal. (2009). Dabigatran versus warfarin in patients with atrial fibrillation. N. Engl. J. Med. 361, 1139-1151.

Coventry and Warwickshire Area Prescribing Committee. (2012). Dabigatran (Pradaxa ${ }^{\circledR}$ ) in Atrial Fibrillation. Available at: http://www. coventry. nhs.uk/CmsDocuments/ f32f3f79-d837-4aed-a3cc-d854cd $58063 \mathrm{e} . \mathrm{pdf}$ (accessed December, 2012).

Davidson, T., Husberg, M., Janzon, M., Oldgren, J., and Levin, A.-K. (2013). Cost-effectiveness of dabigatran compared with warfarin for patients with atrial fibrillation in Sweden. Eur. Heart J. 34 177-183.

Davies, C., and Abraham, J. (2013). Is there a cure for corporate crime in the drug industry? Effective enforcement of regulations requires more resources and determination to impose robust sanctions. $B M J$ 346:f755. doi: 10.1136/bmj.f755
Davies, N., and Jamali, F. (2004). CoxII selective inhibitors cardiac toxicity: getting to the heart of the matter. J. Pharm. Pharm. Sci. 7, 332-336.

Department of Justice. (2010). Settlement Agreement between United States and AstraZeneca. Available at: http://www.justice.gov/usao/pae/ Pharma-Device/astrazeneca settlementagreement.pdf (accessed January 2013).

Dietrich, M., and Horvath, T. (2012). Limitations in anti-obesity drug development: the critical role of hunger-promoting neurons. Nat. Rev. Drug Discov. 11, 675-691.

DiMasi, J. A., and Grabowski, H. G. (2007). The cost of biopharmaceutical R\&D: is biotech different? Manag. Decis. Econ. 28, 469-479.

Douxfils, J., Mullier, F., Robert, S., Chatelain, C., Chatelain, B. and Dogné, J.-M. (2012). Impact of dabigatran on a large panel of routine or specific coagulation assays - laboratory recommendations for monitoring of dabigatran etexilate. Thromb. Haemost. 107, 985-997.

EATG. (2009). 2009 World Pharma Sales Forecast to Top $\$ 820$ Billion. Available at: http://www.eatg.org/eatg/GlobalHIV-News/Pharma-Industry/2009world-pharma-sales-forecast-totop-820-billion (accessed December 2012).

East Lancashire NHS Medicines Management Health Economy New Medicines and Treatments Group Dabigatran for prevention of stroke in non-valvular atrial fibrillation (2012). Available at: http://www. elmmb.nhs.uk/formularies/jointmedicines-formulary/2/2-8/ (accessed December, 2012).

Eichler, H.-G., Abadie, E., Breckenridge, A., Flamion, B., Gustafsson, L. L. Leufkens, H., et al. (2011). Bridging the efficacy-effectiveness gap: a regulator's perspective on addressing variability of drug response. Nat. Rev. 10, 495-506.

Elton, P., Ratcliffe, J., Fitchet, A., White, A., Sutton, A., and Budden, P. (2011). Re: cost of dabigatran for atrial fibrillation. Rapid response. BMJ. Available at: http://www.bmj.com/ content/343/bmj.d6980?tab= responses (accessed December 2012) European Medicines Agency (EMA). (2008). CHMP Assessment Report for Pradaxa (Dabigatran). EMEA/ 174363/2008. Available at: http:// www.ema.europa.eu/docs/en_GB/ document library/EPAR _ Public assessment_report/human/000829/
WC500041062.pdf

(accessed December 2012).

European Medicines Agency (EMA). (2009). Withdrawal of the Marketing Authorisation in the European Union. EMEA/39457/2009. Available at: http://www.emea.europa.eu/docs/ en_GB/document_library/Public statement/2009/11/WC500012189. pdf (Accessed December 2012).

European Medicines Agency (EMA). (2011). Update on Safety of Pradaxa. Available at: http://www.ema.europa. eu/ema/index.jsp?curl=pages/news_ and_events/news/2011/11/news_ detail_001390.jsp\&mid= WC0b01ac058004d5cl (accessed January 2013).

European Medicines Agency (EMA). (2012). Pradaxa - Dabigatran. Available at: http://www.ema.europa. eu/ema/index.jsp?curl=pages/ medicines/human/medicines/ 000829/human_med_000981.jsp\& murl=menus/medicines/medicines. jsp\&mid=WC0b01ac058001d125 (accessed December 2012).

EvaluatePharma. (2012). Surveying Tomorrow's BioPharma Landscape. The NASDAQ Biotech Index Up Close. Available at: http://info.evaluate pharma.com/rs/evaluatepharmaltd/ images/EvaluatePharma_NBI_Up_ Close_2012.pdf (accessed January 2013).

Fagius, J., Osterman, P. O., Siden, A., and Wiholm, B. E. (1985). Guillain-Barré syndrome following zimelidine treatment. J. Neurol. Neurosurg. Psychiatry $48,65-69$.

FDA. (2002). Vioxx (Rofecoxib). Available at: http://www.fda.gov/Safety/ MedWatch/SafetyInformation/Safety AlertsforHumanMedicalProducts/ ucm 154520.htm (accessed January 2013).

Federal Agency for Medicines and Health Products (FAMHP). (2011). Dabigatran Etexilate (PRADAXA): Updated Information. Available at: http://www.fagg-afmps.be/en/news/ news_dabigatran_pradaxa.jsp? referer=tcm:292-153431-64 (accessed February 2013).

Fife Area Drug and Therapeutics Committee. (2012). Area Drug \& Therapeutics Bulletin. Prescribing of newer oral anticoagulants. December 2011-March 2012. Available at: http://www.fifeadtc.scot.nhs.uk/ bulletins/2012/ADTC\%20Bulletin \%20Dec-Mar.pdf [accessed December, 2012].

Fisk, M., Feeley, J., and Voreacos, D. (2012). J\&J Said to Agree to \$2.2 Billion Drug Marketing Accord. Available at: http:// 
www.bloomberg.com/news/201206-11/j-j-said-to-pay-2-2-billionto-end-risperdal-sales-probe.html (accessed January 2013).

Frank, R. (2007). The ongoing regulation of generic drugs. N. Engl. J. Med. 357, 1993-1996.

Friedman, M. A., Woodcock, J., Lumpkin, M. M., Shuren, J. E., Hass, A. E., and Thompson, L. J. (1999). The safety of newly approved medicines: do recent market removals mean there is a problem? JAMA 281, 17281734.

Fritz, J., and Cleland, J. (2003). Effectiveness versus efficacy: more than a debate over language. $J$. Orthop. Sports Phys. Ther. 33, 163-165.

Garattini, L., and Casadei, G. (2011). Risk sharing arrangements: what lessons from Italy? Int. J. Technol. Assess 27, 169-172.

Garattini, S., Bertele, V., Godman, B., Haycox, A., Wettermark, B., and Gustafsson, L. L. (2008). Enhancing the rational use of new medicines across European healthcare systems - a position paper. Eur. J. Clin. Pharmacol. 64, 1137-1138.

Garber, S. T., Sivakumar, W., and Schmidt, R. H. (2012). Neurosurgical complications of direct thrombin inhibitors - catastrophic haemorrhage after mild traumatic brain injury in a patient receiving dabigatran. J. Neurosurg. 116, 1093-1096.

Garuoliene, K., Alonderis, T., and Marcinkevičius, M. (2011a). Pharmaceutical policy and the effects of the economic crisis: Lithuania. Eurohealth 17, 1-4.

Garuoliene, K., Godman, B., Gulbinovič, J., Wettermark, B., and Haycox, A. (2011b). European countries with small populations can obtain low prices for drugs: Lithuania as a case history. Expert Rev. Pharmacoecon. Outcomes Res. 11, 341-347.

Go, A. S., Hylek, E. M., Phillips, K. A., Chang, Y., Henault, L. E., Selby, J. V., etal. (2001). Prevalence of diagnosed atrial fibrillation in adults: national implications for rhythm management and stroke prevention: the anticoagulation and risk factors in atrial fibrillation (ATRIA) study. JAMA 285, 2370-2375.

Godman, B. (2011). Risk Sharing Arrang ements - Guidance for the Future. Available at: http://www.ceestahc. org/pliki/uoc/20110519/uoc20110519 _godman.pdf (accessed December 2012).

Godman, B. (2013). Health authority perspective on biosimilars. $G a B$ J. doi: 10.5639/gabij.2013.0201.010 [Epub ahead of print].
Godman, B., Abuelkhair, M., Vitry, A., Abdu, S., Bennie, M., Bishop, I., et al. (2012a). Payers endorse generics to enhance prescribing efficiency: impact and future implications, a case history approach. GaBi J. 1, 69-83.

Godman, B., Bennie, M., Baumgärtel, C., Sović Brkičić, L., Burkhardt T., Fürst, J., et al. (2012b). Essential to increase the use of generics in Europe to maintain comprehensive health care? Farmecon. Health Econ. Ther. Pathw. 13(Suppl. 3), 5-20.

Godman, B., Malmstrom, R. E., Bennie, M., Sakshaug, S., Burkhardt T., Campbell, S., et al. (2012c). Prescribing restrictions - a necessary strategy among some European countries to enhance future prescribing efficiency? Rev. Health Care 3, 5-16.

Godman, B., Paterson, K., Malmstrom, R., Selke, G., Fagot, J. P., and Mrak, J. (2012d). Improving the managed entry of new medicines: sharing experiences across Europe. Expert Rev. Pharmacoecon. Outcomes Res. 12, 439-441.

Godman, B., Wettermark, B., Bennie, M., Diogéne, E., Van Ganse, E., and Gustafsson, L. L. (2012e). Critical role for clinical pharmacologists and hospital pharmacists with enhancing prescribing efficiency for new and existing drugs. (E)Hospital 14, 1-2 (pharma special).

Godman, B., Wettermark, B., Bishop, I., Burkhardt, T., Fürst, J., Garuoliene, K., et al. (2012f). European payer initiatives to reduce prescribing costs through use of generics. GaBi J. 1, 22-27.

Godman, B., Bucsics, A., Burkhardt, T., Haycox, A., Seyfried, H., and Wieninger, P. (2008). Insight into recent reforms and initiatives in Austria; implications for key stakeholders. Expert Rev. Pharmacoecon. Outcomes Res. 8, 357-371.

Godman, B., Burkhardt, T., Bucsics, A., Wettermark, B., and Wieninger, P. (2009a). Impact of recent reforms in Austria on utilisation and expenditure of PPIs and lipid-lowering drugs; implications for the future. Expert Rev. Pharmacoecon. Outcomes Res. 9 , 475-484.

Godman, B., Schwabe, U., Selke, G., and Wettermark, B. (2009b). Update of recent reforms in Germany to enhance the quality and efficiency of prescribing of proton pump inhibitors and lipid lowering drugs. Pharmacoeconomics 27, 435-438.

Godman, B., Wettermark, B., Hoffman, M., Andersson, K., Haycox, A. and Gustafsson, L. L. (2009c). Multifaceted national and regional drug reforms and initiatives in ambulatory care in Sweden; global relevance. Expert Rev. Pharmacoecon. Outcomes Res. 9, 65-83.

Godman, B., and Gustafsson, L. L. (2013). A new reimbursement systems for innovative pharmaceuticals combining value-based and free market pricing. Appl. Health Econ. Health Policy. 11, 79-82.

Godman, B., Sakshaug, S., Berg, C. Wettermark, B., and Haycox, A. (2011a). Combination of prescribing restrictions and policies to engineer low prices to reduce reimbursement costs. Expert Rev. Pharmacoecon. Outcomes Res. 11, 121-129.

Godman, B., Shrank, W., Andersen, M., Berg, C., Bishop, I., Burkhardt, T., et al. (2011b). Policies to enhance prescribing efficiency in Europe: findings and future implications. Front. Pharmacol. 1:141. doi: 10.3389/fphar.2010.00141

Godman, B., Wettermark, B., Bennie, M., Burkhardt, T., and Garuoliene, K. (2011c). Enhancing prescribing efficiency through increased utilisation of generics at low prices. (E)Hospital $13,28-31$

Godman, B., Shrank, W., Andersen, M., Berg, C., Bishop, I., Burkhardt T., et al. (2010). Comparing policies to enhance prescribing efficiency in Europe through increasing generic utilisation: changes seen and global implications. Expert Rev. Pharmacoecon. Outcomes Res. 10, 707-722.

Griffin, D., and Segal, A. (2010). Feds Found Pfizer too Big to Nail. Available at: http://edition.cnn.com/2010/ HEALTH/04/02/pfizer.bextra/index. html

Gustafsson, L. L., Wettermark, B., Godman, B., Andersén-Karlsson, E., Bergman, U., Hasselström, J., et al. (2011). The "Wise List"- a comprehensive concept to select, communicate and achieve adherence to recommendations of essential drugs in ambulatory care in Stockholm. Basic Clin. Pharmacol. Toxicol. 108, 224-233.

Guthrie, E. (2000). Psychotherapy for patients with complex disorders and chronic symptoms. The need for a new research paradigm. Br. J. Psychiatry 177, 131-137.

Haute Authorite de Sante-Commission de la Transparence. (2012). Pradaxa. Available at: http://www.has-sante.fr/ portail/upload/docs/application/ pdf/2012-03/pradaxa_15022012 avis_ct 10749.pdf (accessed December 2012).

Harper, P., Young, L., and Merriman, E. (2012). Bleeding risk with dabigatran in the frail elderly. N. Engl. J. Med. $366,864-866$

Health Improvement Scotland. (2012). Prevention of stroke and systemic embolism in adult patients with non-valvular atrial fibrillation. Available at: www.healthcareimprove mentscotland.org/programmes/car diovascular_disease/dabigatran_ consensus_statement.aspx [accessed December, 2012).

Heidbüchel, H. T. V., Verhamme, P., Hermans, C., Peeters, A., and Scavée, C. (2011). Practical Guide Dabigatran - Guidance for Use in Particular Situations. Available at: http://www.thrombosisguidelines group.be (accessed December 2012).

Hirschler, B. (2012). Fifty Percent off the First Three months of Cancer Medicine. Buy a Course of Eye Treatment and Get Extra Injections Free. A Money-back Guarantee if Your Erectile Dysfunction Pills Don't Work. Available at: http://www.reuters.com/ article/2012/10/24/us-pharmaceuti cals-europe-pricing-idUSBRE89 N0GQ20121024 (accessed January 2013).

Holmström, M., Johnsson, H., Lärfars, G., Malmström, R., and Hjemdahl, P. (2009). New drug in atrial fibrillation - how does it function in regular health care? Lakartidningen 106, 3019-3020.

Horsley, W. (2010). Dabigatran for the Prevention of Stroke in Patient with Non-valvular Atrial Fibrillation: A Cost Analysis for the NHS North East. NHS North East Treatment Advisory Group. Available at: http:// www.netag.nhs.uk/files/appraisalreports/Dabigatran $\% 20$ NETAG\%20 cost $\% 20$ analysis\%20-Jan2010\%20-\%20web\%20version\%202.pdf (accessed December 2012).

Huisman, M., Lip, G., Diener, H.G., Brueckmann, M., van Ryn, J., and Clemens, A. (2012). Dabigatran etexilate for stroke prevention in patients with atrial fibrillation: resolving uncertainties in routine practice. Thromb. Haemost. 107, 838-847.

IQWiG. (2010). Merkblatt: Gerinnungshemmende Medikamente sicher anwenden. Available at: http://www. gesundheitsinformation.de/index. 624.de.html (accessed January 2013).

Institute for Safe Medication Practices. (2011). Quarter Watch 2010 Quarter 4. Available at: http://www. ismp.org/QuarterWatch/pdfs/2010 Q4.pdf (accessed December 2012).

Interface - A monthly medicines and prescribing bulletin for healthcare professionals in East Lancashire 
focusing on new therapies. (2011). Available at: www.elmmb.nhs.uk/ EasySiteWeb/GatewayLink.aspx?alId $=48664$ (accessed December 2012).

Ioannides-Demos, L., Piccenna, L. and McNeil, J. (2011). Pharmacotherapies for obesity: past, current, and future therapies. J. Obes. 2011, 179674.

Jack, A. (2008). Balancing Big Pharma's books. BMJ 336, 418-419.

Jackevicius, C., Chou, M., Ross, J., Shah, N., and Krumholz, H. (2012) Generic atorvastatin and health care costs. N. Eng. Jn. Med. 366, 201-204.

Janusinfo. (2009). Nya riktlinjer \& behandlingsstrategier. Rekommendati oner avseende antikoagulantiabehandling med warfarin eller dabigatran vid förmaksflimmer. Available at: http://www.janusinfo.se/Documents/ Broschyrer/F\%C3\%B6rskrivarinfo_ f\%C3\%B6rmaksflimmer_A4.pdf (accessed January 2013).

Janusinfo. (2012a). Frågor och svar om dabigatran. Available at: http://www. janusinfo.se/Documents/Expert gruppsdokument/dabigatran_fragor svar_120208.pdf (accessed January 2013)

Janusinfo. (2012b). Välj i första hand warfarin som tromboemboliprofylax vid förmaksflimmer. Följ riktlinjer för warfarinbehandling. Available at: http://www.janusinfo.se/Global/Klok \%20Rad/warfarin_120320.pdf (accessed January 2013).

Jaroslawski, S., and Toumi, M. (2011). Market access agreements for pharmaceuticals in Europe: diversity of approaches and underlying concepts. BMC Health Serv. Res. 11:259. doi: 10.1186/1472-696311-259

Jommi, C. (2012). Managed Market Entry for Drugs in Italy. EMAUD Market Access Newsletter. Available at: http://www.slideshare.net/ Mondher_Toumi/market-accessnewsletter-emaud-june 2012 (accessed December 2012).

Joppi, R., Cinconze, E., Mezzalira, M., Pase, D., Poggiani, C., Rossi, E., et al. (2013). Hospitalized patients with atrial fibrillation compared to those included in recent trials on novel oral anticoagulants: A populationbased study. Eur. J. Intern. Med. doi: 10.1016/j.ejim.2013.02.018 [Epub ahead of print].

Kaiser, J. (2012). New cystic fibrosis drug offers hope, at a price. Science 335, 645.

Kalaba, M., Godman, B., Vuksanovic, A., Bennie, M., and Malmstrom, R. E. (2012). Possible ways to enhance renin-angiotensin prescribing efficiency: Republic of Serbia as a case history? J. Comp. Eff. Res. 1, 539-549.

Kansal, A. R., Sorensen, S. V., Gani, R., Robinson, P., Pan, F. Plumb, J. M., et al. (2012). Costeffectiveness of dabigatran etexilate for the prevention of stroke and systemic embolism in UK patients with atrial fibrillation. Heart 98, 573-578.

Kappos, L., Bates, D., and Edan, G. (2011). Natalizumab treatment for multiple sclerosis: updated recommendations for patient selection and monitoring. Lancet Neurol. 10, 745-758.

Keegan, B. (2011). Natalizumab for multiple sclerosis: a complicated treatment. Lancet Neurol. 10 , 677-678.

Keele University School of Pharmacy. (2012). Medicines Management Effective Shared Care Agreement Toolkit - Dabigatran. Available at: http://www.esca-keele.co.uk dabigatran/ (accessed January 2013).

Kirchhof, P., Auricchio, A., Bax, J., Crijns, H., Camm, J., Diener, H. C., et al. (2007). Outcome parameters for trials in atrial fibrillation: executive summary. Recommendations from a consensus conference organized by the German Atrial Fibrillation Competence NETwork (AFNET) and the European Heart Rhythm Association (EHRA). Eur. Heart J. 28, 2803 2817.

Kirsch, I., Deacon, B. J., Huedo-Medina T. B., Scoboria, A., Moore, T. J., Johnson, B. T., et al. (2008). Initial severity and antidepressant benefits: a meta analysis of data submitted to the Food and Drug Administration. PLoS Med. 5:e45. doi: 10.1371/journal.pmed.0050045

Klemp, M., and Frønsdal, K. (2011). What principles should govern the use of managed entry agreements? Int. J. Technol. Assess. Health Care 27, 77-83.

Kmietowicz, Z. (2013). GSK backs campaign for disclosure of trial data. $B M J$ 346, f819.

Kolasa, K., Schubert, S., Manca, A., and Hermanowski, T. (2011). A review of Health Technology Assessment (HTA) recommendations for drug therapies issued between 2007 and 2009 and their impact on policymaking processes in Poland. Health Policy 102, 145-151.

Kreatinin-Clearance Rechner (Creatinine Clearance calculator) (2013). Cocktroft-Gault Formula.
Available at: http://www.dialysehamburg.de/kreacal.htm (accessed January 2013).

KVH - Aktuell. (2010). Informationsdienst der Kassenärztlichen Vereinig ung Hessen Pharmakotherapie. Available at: http://www.kvberlin.de/40 presse/50publikation/20pharmakoth erapie/2010/pharmakotherapie_ 1001.pdf (accessed December 2012).

Legrand, M., Mateo, J., Aibaud, A. Ginisty, S., Eftekhari, P., Huy, P. T., et al. (2011). The use of dabigatran in elderly patients. Arch. Intern. Med. 8, 432-439.

Lexchin, J., and Kohler, J. (2011). The danger of imperfect regulation: OxyContin use in the United States and Canada. Int. J. Risk Saf. Med. 23, 233-240.

Liesenfeld, K. H., Lehr, T., Dansirikul, C., Reilly, P. A., Connolly, S. J. Ezekowitz, M. D., et al. (2011). Population pharmacokinetic analysis of the oral thrombin inhibitor dabigatran etexilate in patients with nonvalvular atrial fibrillation from the RE-LY trial. J. Thromb. Haemost. 9, 2168-2175.

Lloyd-Jones, D. M., Wang, T. J., Leip, E. P., Larson, M. G., Levy, D., Vasan, R. S., et al. (2004). Lifetime risk for development of atrial fibrillation: the Framingham Heart Study. Circulation 110, 1042-1046.

Lothian Prescribing Bulletin. (2012) Oral anticoagulants - what's new? Available at: http://www.ljf.scot.nhs uk/PrescribingBulletins/Prescribing \%20Bulletins/Lothian\%20Prescrib ing $\% 20$ Bulletin $\% 20$ Issue $\% 2055 \% 20$ May\%202012\%20FINAL.pdf (accessed December 2012)

Luengo-Fernandez, R., Gray, A. M., and Rothwell, P. M. (2006). Populationbased study of determinants of initial secondary care costs of acute stroke in the United Kingdom. Stroke 37, 2579-2587.

Malmström, R. E. (2009). "New anticoagulants," in Essential Guide to Blood Coagulation, eds J. P. Antovic and M. Blombäck (Oxford: Wiley-Blackwell Publishing), 91-102.

Mannuci, M., Nobil, A., and Garattini, S. (2012). New drug for thromboprophylaxis in atrial fibrillation. Eur. J. Intern. Med. 23, $1-5$.

Markovic-Pekovic, V., Škrbić, R., Godman, B., and Gustafsson, L. L. (2012). Ongoing initiatives in the Republic of Srpska to enhance prescribing efficiency; influence and future direction. Expert Rev. Pharmacoecon. Outcomes Res. 5, 661-671.
Marshall, S., Fearon, P., Dawson, J., and Quinn, T. (2013). Stop the clots, but at what cost? Pharmacoeconomics of dabigatran etexilate for the prevention of stroke in subjects with atrial fibrillation: a systematic literature review. Expert Rev. Pharmacoecon. Outcomes Res. 13, 29-42.

Martikainen, J., Saastamoinen, L., Korhonen, M., Enlund H., and HelinSalmivaara, A. (2010). Impact of restricted reimbursement on the use of statins in Finland. Med. Care 48, 761-766.

Martin, D. (2012). Drug Firms are 'Risking Lives by Hiding Bad Trials and Side Effects of Their Medicines'. Available at: http:// www.dailymail.co.uk/news/article2222220/Drug-firms-risking-

lives-hiding-bad-trials-effectsmedicines.html?ito=feeds-newsxml) (accessed November 12, 2012).

McGinn, D., Godman, B., Lonsdale, J., Way, R., Wettermark, B., and Haycox, A. (2010). Initiatives to enhance the quality and efficiency of statin and PPI prescribing in the UK: impact and implications. Expert Rev. Pharmacoecon. Outcomes Res. 10, 73-85.

Medicine Balance (MEDICIJNBALANS). (2012). Oral Anticoagulants. Available at: http://www.medicijn balans.nl/medicijngroepen/oraleanticoagulantia (accessed December 2012).

Medicin \& Läkemedel. (2012). Entid NINGfrånStockholmsläns läkemedelskommittéhäls o- ochsjukvårdsförvaltni $n$ ge n. Frågor \& svar om dabigatran Expertråden ger svar på frågor om nytt antikoagulantium. Available at: http: //www.janusinfo.se/publikationer/ evidens/nr01/files/assets/seo/page1. html (accessed December 2012).

Melander, H., Ahlqvist-Rastad, J., Meijer, G., and Beermann, B. (2003). Evidence b(i)ased medicine - selective reporting from studies sponsored by pharmaceutical industry: review of studies in new drug applications. BMJ 326, 11711173.

Mello, M. M., Abiola, S., and Colgrove, J. (2012). Pharmaceutical companies' role in state vaccination policymaking: the case of human papillomavirus vaccination. Am. J. Public Health. 102, 893-898.

Merck. (2002). Important Prescribing Information. Available at: http:// www.fda.gov/downloads/Safety/Med Watch/SafetyInformation/Safety AlertsforHumanMedicalProducts/ 
UCM171089.pdf (accessed January 2013).

Merck. (2004). Merck Announces Volun tary Worldwide Withdrawal of VIO$X X^{\circledR}$. Available at: http://www.pbm. va.gov/vioxx/Dear\%20Healthcare\% 20Professional.pdf (accessed January 2013)

MHRA UK. (2004). Immediate Withdrawal of Rofecoxib (Vioxx/Vioxxacutate). Available at: http://www. mhra.gov.uk/Safetyinformation/ Safetywarningsalertsandrecalls/ Safetywarningsandmessagesfor medicines/CON1004263 (accessed January 2013).

Midlands Therapeutic Review and Advisory Committee (MTRAC). (2012). COMMISSIONING GUIDANCE Dabigatran Etexilate for Stroke Prevention in Patients with Atrial Fibrillation. Available at: http://www. keele.ac.uk/media/keeleuniversity/ fachealth/fachealthsop/mtrac/ documents/summary/Dabigatran\% 20VS\%2012.pdf (accessed December 2012).

Mismetti, P., and Laporte, S. (2010). New oral antithrombotics: a need for laboratory monitoring. J. Thromb. Haemost. 8, 621-626.

Moreira, F., Alexandre, J., and Crippa, S. (2009). The psychiatric side-effects of rimonabant. Rev. Bras. Psiquiatr. 31, 145-153.

Mullard, A. (2012). 2011 FDA drug approvals. Nat. Rev. Drug Discov. 11, 91-94.

Nagle, P. C., Nicita, C. A., Gerdes, L. A., and Schmeichel, C. J. (2008). Characteristics of and trends in the late-stage biopharmaceutical pipeline. Am. J. Manag. Care 14, 226-229.

National Cancer Institute. (2010). Surveillance Epidemiology and End Results (SEER). Washington, DC: National Cancer Institute [online]. Available at: http://seer.cancer.gov/ (accessed December 2012).

National Centre for Pharmacoeconomics. (2011). Dabigatran Etexilate (Pradaxa ${ }^{\circledR}$ ) for the Prevention of Stroke and Systemic Embolism in Adult Patients with Atrial Fibrillation. Available at: http://www. ncpe.ie/drugs/dabigatran-etexilatepradaxa-for-the-prevention-ofstroke-and-systematic-embolisomin-atrial-fibrillation/ (accessed December 2012).

National Institute for Health and Clinical Excellence. (2012). Dabigatran Etexilate for the Prevention of Stroke and Systemic Embolism in Atrial Fibrillation. NICE Technology Appraisal Guidance 249. Available at: http://www.nice.org.uk/nicemedia/ live/13677/58470/58470.pdf

(accessed December 2012).

Neue Arzneimittel. (2011). Information der Arzneimittelkommission der deutschen Ärzteschaft (Akd̈̈) Pradaxa $^{\circledR}$ (Dabigatran) - neu zugelassene Indikation. Available at: http:// www.akdae.de/Arzneimitteltherapie/ NA/Archiv/2011030-Pradaxa.pdf (accessed December 2012).

NHS Cumbria, NHS Lancashire. (2012a). Consensus statement: Oral anti-coagulant drugs for the prevention of stroke and systemic embolism in adult patients with non-valvular atrial fibrillation. Available at: http://www. cumbria.nhs.uk/ProfessionalZone/ MedicinesManagement/Guidelines/ NOAC-Consensus-Statement.pdf (Accessed December 2012).

NHS Cumbria, NHS Lancashire. (2012b). Guidance for prescribing of dabigatran in patients with non-valvular AF. Available at: http://www.cumbria.nhs.uk/ ProfessionalZone/MedicinesManage ment/Guidelines/Prescribing-Guid ance-for-NOACs.pdf (accessed December, 2012).

NHS Highland - The Pink One. (2012). Dabigatran recommended for specific patient groups. December 2011 to January 2012. Available at: http://www.nhshighland.scot.nhs.uk/ Publications/Documents/Newsletters /Pharmacy/The\%20Pink\%20One $\% 20$ No\%2095\%20December\%20 2011\%20-\%20January\%202012.pdf (accessed December, 2012).

NHS Improvement. Guidance on Risk Assessment and Stroke Prevention for Atrial Fibrillation (GRASP AF). (2013). Available at: http:// www.improvement.nhs.uk/graspaf/ (accessed February 2013).

NHS Tayside. (2011). Dabigatran, Tayside Prescriber Supplement No. 112. December 2011. Available at: http://www.nhstaysideadtc.scot. nhs.uk/approved/bulletin/adtcsupp/ 2011/No\%20112.pdf (accessed December 2012).

NPS MEDICINEWISE. (2012). Delay in PBS Listing of Dabigatran. Available at: http://www.nps.org.au/ publications/health-professional/ nps-direct/2012/delay-in-PBSlisting?utm_source=nps-direct\&utm _medium=email\&utm_campaign $=$ issue-3-2013 (accessed January 2013).

Oral anticoagulants. (2012). What's new? LOTHIAN PRESCRIB ING BULLETIN. Issue 65, May 2012. Available at: http://www. ljf.scot.nhs.uk/PrescribingBulletins/
Prescribing\%20Bulletins/Lothian \%20Prescribing\%20Bulletin\%20 Issue $\% 2055 \% 20 \mathrm{May} \% 202012 \% 20$ FINAL.pdf [accessed December 2012].

Ostazen 2011. Consensus statement on Dabigatran - Sociedad Vasco Navarra de Cardiología, Sociedad Vasca de Medicina de Familia y Comunitaria (OSATZEN), Sociedad de Neurología del País Vasco, Asociación del Norte de Hematología-Hemoterapia, Sociedad de Medicina Interna País Vasco, Sociedad Vasca de Farmacia Hospitalaria, y la vocalía de Euskadi de la Sociedad Española de Farmacéuticos de Atención Primaria 2011. (2011). Available at: http://www.osakidetza. euskadi.net/r85-pkcevi02/es/con tenidos/informacion/cevime_ atencion_primaria/es_cevime/ r01hRedirectCont/contenidos/ informacion/cevime_nuevo_ medicamento/es_nme/adjuntos /Consenso_dabigatran_c_bis. pdf (accessed December, 2012).

O’Shaughnessy. (2009). Adieu Rimonabant. Available at: http://www. beyondthc.com/wp-content/ uploads/2012/05/2009AdieuRimona bant.pdf (accessed December 2012).

Östergötland. (2012). Strukturerat införande av nya antikoagulantia $i$ Östergötland - Dabigatran 111011. Available at: http://www.lio. se/pages/142057/Baseline-formulär\% 20och\%20checklista\%20Dabigatran \%205\%20111011.pdf (accessed December 2012).

Ozierański, P., McKee, M., and King, L. (2012). Pharmaceutical lobbying under postcommunism: universal or country-specific methods of securing state drug reimbursement in Poland? Health Econ. Policy Law 7, 175-195.

Papeix, C., Vukusic, S., Passante, N., Ionescu, I., Frangoulis, B., Stankoff, S., etal. (2012). Natalizumab Discontinuation in Clinical Practice: A Systematic Observational Study from the National TYSEDMUS Cohort of Multiple Sclerosis Patients Treated with Natalizumab in France. Available at: http:// registration.akm.ch/einsicht.php?XN ABSTRACT_ID $=137397 \& X N S P R A$ CHE ID $=2 \& X N K O N G R E S S$ ID $=$ $150 \& X N M A S K E N \_I D=900$ (accessed December 2012).

Persson, U., Svensson, J., and Pettersson, B. (2012). A new reimbursement system for innovative pharmaceuticals combining value-based and free market pricing. Appl. Health Econ. Health Policy 10, 217-225.
Pink, J., Lane, S., Pirmohamed, M., Dyfrig, A., and Hughes, D. (2011). Dabigatran etexilate versus warfarin in management of non-valvular atrial fibrillation in UK context: quantitative benefit-harm and economic analyses. BMJ 343, d6333.

Reicin, A., Barr, E., and Shapiro, D. (2001). Cardiovascular safety profile of rofecoxib: a meta-analysis. Arthritis Rheum. 44, S372;S230; S266.

Rodriguez, R., Carrier, M., and Wells, P. (2013). Non-adherence to new oral anticoagulants: a reason for concern during long-term anticoagulation? Int. Soc. Thromb. Haem. 11, 390-394.

Rolfe, S., Papadopoulos, S., and Cabral, K. P. (2010). Controversies of anticoagulation reversal in life-threatening bleeds. J. Pharm. Pract. 23, 217-225.

Scottish Medicines Consortium. (2011). Dabigatran Etexilate $110 \mathrm{mg}$ and 150 mg Hard Capsules (Pradaxa ${ }^{\circledR}$ ) SMC No. (672/11). Available at: http://www.scottishmedicines.org. uk/files/advice/dabigatran_Pradaxa_ FINAL_August_2011_Amended_ 05.09.11_for_website.pdf (accessed December 2012).

Selyukh, A. (2011). Seattle Genetics Cancer Drug Price May Top $\$ 100,000$. Available at: http://www. reuters.com/article/2011/08/22/usseattlegenetics-idUSTRE77L5EB201 10822 (accessed February 2013).

Sermet, C., Andrieu, V., Godman, B., Van Ganse, E., Haycox, A., and Reynier, J. P. (2010). Ongoing pharmaceutical reforms in France; implications for key stakeholder groups. Appl. Health Econ. Health Policy 8, 7-24.

Shuchman, M. (2006). Delaying generic competition - corporate payoffs and the future of Plavix. N. Engl. J. Med. 355, 1297-1300.

Siviero, P., Sammarco, A., Tafuri, G., and Pani, L. (2012). An HTA approach for pricing and reimbursement decisions: the Italian experience with managed entry agreements. Gac. Sanit. 26, 280.

Southworth, M., Reichman, M., and Unger, E. (2013). Dabigatran and postmarketing reports of bleeding. N. Engl. J. Med. doi: 10.1056/NEJMp1302834 [Epub ahead of print].

Stangier, J., and Clemens, A. (2009). Pharmacology, pharmacokinetics, and pharmacodynamics of dabigatran etexilate, an oral direct thrombin inhibitor. Clin. Appl. Thromb. Hemost. 15(Suppl. 1), 9S-16S. 
Stangier, J., Stahle, H., Rathgen, K., and Fuhr, R. (2008). Pharmacokinetics and pharmacodynamics of the direct oral thrombin inhibitor dabigatran in healthy elderly subjects. Clin. Pharmacokinet. 47, 47-59.

Stewart, S., Hart, C. L., Hole, D. J., and McMurray, J. J. (2001). Population prevalence, incidence, and predictors of atrial fibrillation in the Renfrew/Paisley study. Heart 86, 516-521.

Stewart, S., Murphy, N., Walker, A., McGuire, A., and McMurray, J. J. (2004). Cost of an emerging epidemic: an economic analysis of atrial fibrillation in the UK. Heart 90, 286-292.

Stockholms läns landsting. (2011). Prognos över användning och kostna der för läkemedel $i$ SLL 20112012. Available at: http://www.janus info.se/Documents/Lakemedelsstati stik/Prognos\%202011_2012_110420 \%20final.pdf (accessed January 2013).

Stollberger, C., and Finsterer, J. (2013). Concerns about storage and application of dabigatran and rivaroxaban. Eur. J. Clin. Pharmacol. 69, 739-740.

Sullivan, R., Peppercorn, P., Sikora, K., Zalcberg, J., Meropol, N. J., Amir, E., et al. (2011). Delivering affordable cancer care in highincome countries. Lancet Oncol. 12, 933-980.

Swedish Council on Health Technology Assessment. (2011) Dabigatran för att förebygga stroke vid förmaksflimmer. Stockholm: Statens beredning för medicinsk utvärdering (SBU). SBU Alert-rapport nr 2011-04. Available at: http://www.sbu.se; in English: http://www.sbu.se/en/Published/ Alert/Dabigatran-to-Prevent-Strokein-Patients-With-Atrial-Fibrillation/ (accessed December 2012).

Taylor, L. (2011). Australian Govt Blocks Subsidies for New Drugs. Available at: http://www.pharmatimes.com/Article /11-03-15/Australian_govt_blocks_ subsidies_for_new_drugs.aspx (accessed December 2012).

Ten Cate, H. (2012). Monitoring new oral anticoagulants, managing thrombosis, or both? Thromb. Haemost. 107, 803-805.

Therapie Tipps. (2012). Wiener Gebietskrankenkasse p. 23 Issue 2. Available at: http://www.wgkk.at/ mediaDB/874712_therapietipps_ sb_2_2012.pdf (accessed December 2012).

Thompson, A. (2010). NDA 22-512 Dabigatran - Efficacy Review. Available at: http://www.fda.gov/downloads/ AdvisoryCommittees/Committees MeetingMaterials/Drugs/Cardiovascul arandRenalDrugsAdvisoryCommittee/ UCM226704.pdf?utm_campaign= Google2\&utm_source=fdaSearch\&utm _medium=website\&utm_term $=$ dabiga tran\&utm_content $=10 \quad$ (accessed December 2012).

UK Medicines Information. (2012). New Drugs Online Report for Vemurafenib. Available at: http://www.ukmi. nhs.uk/applications/ndo/record view_open.asp?newDrugID $=5009$ (accessed December 2012).

UKMi Medicines Information. (2013). New Drugs Online Report for Crizotinib. Available at: http://www.ukmi. nhs.uk/applications/ndo/record_view _open.asp?newDrugID=5097 (accessed February 2013).

van Woerkom, M., Piepenbrink, J. F., Godman, B., Metz, J., Campbell, S., Bennie, M., et al. (2012). Ongoing measures to enhance the efficiency of prescribing of proton pump inhibitors and statins in The Netherlands: influence and future implications. J. Comp. Eff. Res. 1, 527-538.

Vogler, S., Zimmermann, N., Habl, C., Piessnegger, J., and Bucsics, A. (2012). Discounts and rebates granted to public payers for medicines in European countries. South Med. Rev. 5 , $38-46$.

Voncina, L., and Strizrep, T. (2011) Croatia: 2009/2010 pharmaceutical pricing and reimbursement reform. Eurohealth 16, 20-22.

Vončina, L., Strizrep, T., Godman, B. Bennie, M., Bishop, I., Campbell, S., et al. (2011). Influence of demand side measures to enhance reninangiotensin prescribing efficiency in Europe; implications for the future. Expert Rev. Pharmacoecon. Outcomes Res. 11, 469-479.

Weir, M. R., Sperling, R. S., Reicin, A., and Gertz, B. J. (2003). Selective COX-2 inhibition and cardiovascular effects: a review of the rofecoxib development program. Am. Heart J. 146, 591-604.

Wells, K. B. (1999). Treatment research at the crossroads: the scientific interface of clinical trials and effectiveness research. Am. J. Psychiatry 156, 5-10. Wettermark, B., Godman, B., Andersson, K., Gustafsson, L. L., Haycox,
A., and Bertele, V. (2008). Recent national and regional drug reforms in Sweden - implications for pharmaceutical companies in Europe. Pharmacoeconomics 26, 537-550.

Wettermark, B., Godman, B., Eriksson, C., van Ganse, E., Garattini, S., Joppi, R., et al. (2010a). Einführung neuer Arzneimittel in europäische Gesundheitssysteme. GGW 10, 24-34. (Introduction of new medicines into European healthcare systems).

Wettermark, B., Godman, B., Neovius, M., Hedberg, N., Mellgren, T. O., and Kahan, T. (2010b). Initia effects of a reimbursement restriction to improve the cost-effectivenes of antihypertensive treatment. Health Policy 94, 221-229.

Wettermark, B., Persson, M., Wilking, N., Kalin, M., Korkmaz, S. Hjemdahl, P., et al. (2010c). Forecasting drug utilization and expenditure in a metropolitan health region. BMC Health Ser. Res. 10:128. doi: 10.1186/1472-6963-10-128

Wettermark, B., Godman, B., Jacobsson, B., and Haaijer-Ruskamp, F. (2009a). Soft regulations in pharmaceutical policymaking - an overview of current approaches and their consequences. Appl. Health Econ. Health Policy 7, 137-147.

Wettermark, B., Pehrsson, A., JuhaszHaverinen, M., Veg, A., Edlert, M., Törnwall-Bergendahl, G., et al (2009b). Financial incentives linked to self-assessment of prescribing patterns - a new approach for quality improvement of drug prescribing in primary care. Qual. Prim. Care 17, 179-189.

Wong, D., Sullivan, K., and Heap, G. (2012). The pharmaceutical market for obesity therapies. Nat. Rev. Drug Discov. 11, 669-670.

Wood, S. (2011). Deaths Prompt Dabigatran Safety Advisory in Japan. Available at: http://www.theheart. org/article/1264365.do (accessed December 2012).

World Health Organisation (WHO). (2009). Guidelines for ATC Classification and DDD Assignment. Oslo: WHO Collaborating Centre for Drug Statistics Methodology. Available at: www.whocc.no (accessed December 2012).

Yukhananov, A. (2011). Reuters. Available at: http://www.reuters. com/article/2011/08/26/fda-pfizer-

\section{idUSN1E77P1UG20110826}

(accessed December 2012).

Conflict of Interest Statement: There are no conflicts of interest from any author. However, the majority of authors are employed by health authorities, health insurance companies, universities, or Physician Associations or are advisers to them. The content of the paper and the conclusions are those of each author and may not necessarily reflect those of the organization that employs them.

Received: 04 January 2013; accepted: 20 March 2013; published online: 14 May 2013.

Citation: Malmström RE, Godman BB, Diogene E, Baumgärtel C, Bennie $M$, Bishop I, Brzezinska A, Bucsics A, Campbell $S$, Ferrario A, Finlayson AE, Fürst J, Garuoliene K, Gomes M, GutiérrezIbarluzea I, Haycox A, Hviding K, Herholz H, Hoffmann M, Jan S, Jones J, Joppi R, Kalaba M, Kvalheim C, Laius $O$, Langner I, Lonsdale J, Lööv $S-\AA$, Malinowska $K$, McCullagh L, Paterson K, Markovic-Pekovic V, Martin A, Piessnegger J, Selke G, Sermet C, Simoens $S$, Tulunay $C$, Tomek D, Vonèina $L$, Vlahovic-Palcevski V, Wale J, Wilcock M, Wladysiuk $M$, van Woerkom M, Zara C and Gustafsson LL (2013) Dabigatran a case history demonstrating the need for comprehensive approaches to optimize the use of new drugs. Front. Pharmacol. 4:39. doi: 10.3389/fphar.2013.00039

This article was submitted to Frontiers in Pharmaceutical Medicine and Outcomes Research, a specialty of Frontiers in Pharmacology.

Copyright (c) 2013 Malmström, Godman, Diogene, Baumgärtel, Bennie, Bishop, Brzezinska, Bucsics, Campbell, Ferrario, Finlayson, Fürst, Garuoliene, Gomes, Gutiérrez-Ibarluzea, Haycox, Hviding, Herholz, Hoffmann, Jan, Jones, Joppi, Kalaba, Kvalheim, Laius, Langner, Lonsdale, Lööv, Malinowska, McCullagh, Paterson, Markovic-Pekovic, Martin, Piessnegger, Selke, Sermet, Simoens, Tulunay, Tomek, Vonèina, VlahovicPalcevski, Wale, Wilcock, Wladysiuk, van Woerkom, Zara and Gustafsson. This is an open-access article distributed under the terms of the Creative Commons Attribution License, which permits use, distribution and reproduction in other forums, provided the original authors and source are credited and subject to any copyright notices concerning any third-party graphics etc. 


\section{APPENDIX}

Table A1 | Examples of health authority and health insurance company activities regarding dabigatran for the prevention of stroke in adults with non-valvular AF among European countries to the beginning of 2013 (building on EU marketing authorisation - (Boehringer Ingelheim, 2011a; Marshall et al., 2013).

\section{Country Date dabigatran Summary of activities \\ reimbursed for AF}

Austria (Godman February 2012

et al., 2008, 2009a;

Wettermark etal., 2009a; Vončina

etal., 2011;

Therapie Tipps,

2012)

\section{Post-launch}

Enforcement - Ex ex-ante approval by the head physician of the patient's social health insurance fund before reimbursement of dabigatran; otherwise $100 \%$ co-payment (mirroring other situations). This is now fully automated, with the first prescription typically taking approximately $30 \mathrm{~min}$ to approve

The renal function has to be assessed and recorded prior to initiation of therapy with dabigatran through determining Creatinine-Clearance $(\mathrm{CrCl})$ levels to exclude patients with severe renal dysfunction $(=\mathrm{CrCl}<$ $30 \mathrm{ml} / \mathrm{min}$ ). In addition during treatment, renal function has to be monitored where a decline is envisaged, e.g., patients with hypovolaemia, dehydration and the use of specific additional medication, and renal function has to be assessed at least once a year in patients aged 75 or older, and/or in patients with compromised renal function. Otherwise $100 \%$ co-payment

Health Insurers (WGKK - Vienna) have also stated that patients who are well adjusted on Vitamin K antagonists should not be switched to dabigatran as there is no additional clinical benefit, enhanced by currently no known antidote.

\section{Belgium}

August 2012

(Federal Agency for

Medicines and

Health Products

(FAMHP), 2011) (i) Reimbursement

- $2 \times 150 \mathrm{mg}$ per day based on the SPC and the patient is not subject to one of the following:

- Older than 80 years;

- Treated with verapamil;

- Serious renal insufficiency

- $2 \times 110 \mathrm{mg}$ dose - reimbursed in the absence of serious renal insufficiency but without age or verapamil restrictions

(ii) Education (pre-launch)

- 25th November 2011, the Federal Agency for Medicines and Health Products issued an update concerning the risk of fatal bleeding with dabigatran. This was based on the CHMP's recommendations at the EMA that precautionary measures need to be strengthened in the case of renal insufficiency. Physicians were also informed of the CHMP recommendations in a letter

- In March 2012, the Belgian Centre for Pharmacotherapeutic Information stated that:

- Based on the currently available studies, dabigatran and rivaroxaban appear to be as efficacious as warfarin in the prevention of thrombo-embolism in non-valvular atrial fibrillation

- Their risk-benefit ratio did not seem to be superior to VKAs when VKAs were used in appropriate doses within the INR range

- Awaiting additional studies, and taking into account the limited data and high price of NOACs, VKAs remain the first choice for many patients

- Dabigatran and rivaroxaban can be alternatives in patients for whom treatment with a VKA is difficult to control

- In the absence of comparative studies between dabigatran and rivaroxaban, there are no arguments to prefer one product to the other

- NOACs can lead to specific medicine interactions (but to a lesser extent than with VKAs) and to over-dosing when renal function declines (need to pay attention in the elderly). 


\section{Table A1 | Continued}

\section{Country Date dabigatran Summary of activities \\ reimbursed for $A F$}

\begin{tabular}{|c|c|}
\hline & $\begin{array}{l}\text { Peri-launch (Enforcement) } \\
\text { - Dabigatran was reimbursed as a chapter IV medicine in AF patients. A chapter IV medicine can only be } \\
\text { prescribed subject to prior approval from the advising physician of the patient's health insurance fund - } \\
\text { otherwise a } 100 \% \text { patient co-payment applies } \\
\text { - Reimbursement is restricted to one pack of } 60 \times 150 \mathrm{mg} \text { and three packs of } 180 \times 150 \mathrm{mg} \text {, with a } \\
\text { maximum validity period of } 300 \text { days } \\
\text { - Reimbursement can subsequently be extended for renewable periods of } 360 \text { days for four packs of } \\
180 \times 150 \text { mg per period } \\
\text { - Concomitant reimbursement of dabigatran with another oral anticoagulant is not allowed } \\
\text { Post-launch (Education, Engineering) } \\
\text { - As part of the risk management plan for dabigatran, a warning card/patient card was made available for } \\
\text { patients to keep with them at all times } \\
\text { - By giving this card to patients, it is envisaged that physicians and pharmacists will enhance the } \\
\text { appropriate use of dabigatran and limit potential side effects - especially as the patient is encouraged to } \\
\text { show this card to every physician, pharmacist or other health professional }\end{array}$ \\
\hline Under evaluation & $\begin{array}{l}\text { Reimbursed for the prevention of venous thromboembolism in patients undergoing hip or knee surgery, } \\
\text { and only in hospitals, with prescriptions traced in hospitals if abuse is suspected. } \\
\text { Under consideration for the prevention of stroke and systemic embolism in adult non-valvular AF patients } \\
\text { including price:volume agreements and/ or co-payments. There are also ongoing discussions regarding } \\
\text { safety issues }\end{array}$ \\
\hline
\end{tabular}

\section{England (Horsley, \\ August 2011}

2010; Elton etal.,

2011; Keele

University School

of Pharmacy, 2012;

Midlands

Therapeutic Review

and Advisory

Committee

[MTRAC], 2012;

National Institute

for Health and

Clinical Excellence,

2012; Marshall

etal., 2013; NHS

Improvement.

Guidance on Risk

Assessment and

Stroke Prevention

for Atrial Fibrillation

(GRASP - AF),

2013)

\section{Post-launch}

(A) National - NICE:

Dabigatran is recommended in line with the licenced indication, with the decision whether to start treatment made after an informed discussion between clinicians and patients about the risks and benefits of dabigatran versus warfarin.

For patients already on warfarin, the potential risks and benefits of switching to dabigatran should be considered in light of current INR control.

(B) Regions (Midlands - MTRAC) - Education

Guidance stating that warfarin remains the first-line option for anticoagulation in patients with AF at high risk of a stroke, and PCTs should ensure optimal existing warfarin therapy services - including access to INR clinics, use of computerised decision-support software, and access to drugs for patients who are allergic to warfarin (the latter is rare in practice)

In view of the considerable financial implications, dabigatran treatment should only be prescribed for those patients:

- with co-morbidities who are adherent to warfarin monitoring and lifestyle requirements but need frequent co-prescribed medications that interact with warfarin and affect the patients' time in the therapeutic range (TTR)

- who are adherent to monitoring and lifestyle requirements but whose TTR remains unacceptable despite attempts to optimise treatment with warfarin (TTR rates should be set locally)

Alongside this, patient follow-up via agreed shared care protocols with ongoing monitoring of prescribing costs and feedback from Pharmaceutical Advisers. 
Table A1 | Continued

\begin{tabular}{|c|c|c|}
\hline Country & $\begin{array}{l}\text { Date dabigatran } \\
\text { reimbursed for AF }\end{array}$ & Summary of activities \\
\hline & & (C) Localities \\
\hline Coventry and & & (i) Coventry and Warwickshire Area Prescribing Committee (Education, engineering): \\
\hline Warwickshire Area & & - Dabigatran should only be initiated by a specialist \\
\hline Prescribing & & - Follow on prescribers should receive a checklist from the initiating specialist indicating patients are \\
\hline Committee (2012); & & suitable for dabigatran and have received appropriate guidance from the specialist \\
\hline Interface - A & & - No follow-on prescribing if checklist is unavailable from the specialist \\
\hline monthly medicines & & \\
\hline and prescribing & & (ii) East Lancashire (Education): \\
\hline bulletin for & & Initially not approved (October 2011); but subsequently approved for usage in January 2012. As part of this: \\
\hline healthcare & & \\
\hline professionals in & & - Patients currently stable on warfarin therapy should not be considered for dabigatran. \\
\hline East Lancashire & & - Dabigatran should only be considered for prescribing by appropriate specialists (including GPs \\
\hline focusing on new & & initiating therapy as part of specially commissioned anti-coagulation services) \\
\hline therapies (2011); & & - Dabigatran should only be considered as an alternative to warfarin for stroke prevention in AF patients \\
\hline East Lancashire & & in the following: \\
\hline NHS Medicines & & 1. Patients for whom warfarin is contraindicated or not tolerated or not suitable (e.g., Mental/cognitive \\
\hline Management & & impairment) - NOTE: If warfarin is contra-indicated due to increased bleeding risk then dabigatran \\
\hline Health Economy & & would also be contra-indicated. \\
\hline New Medicines & & 2. Patients who are poorly controlled on warfarin, i.e. a clinical judgement based on patient reviews \\
\hline and Treatments & & relating to the extent INR results are outside of the target therapeutic range (TTR). If dabigatran is \\
\hline Group - Dabigatran & & considered as a suitable alternative, prescribers must fully document the rationale \\
\hline
\end{tabular}

for prevention of

stroke in

non-valvular atrial

fibrillation (2012);

NHS Cumbria, NHS

Lancashire

(iii) NHS Bury

- Greater Manchester Medicines Group [GMMMG] and the Greater Manchester and Cheshire Cardiac and Stroke Network [GMCCSN] agreed joint guidance for the use of dabigatran behind warfarin. This resulted in NHS Bury establishing a "Gateway" whereby GPs had to seek permission from NHS Bury to prescribe dabigatran

- This resulted in very few requests, with even fewer requests granted due to ongoing clinical and economic concerns.

- Following NICE advice [TA249], NHS Bury have instigated a number of educational activities with Consultants and GPs including joint symposia and the production of local prescribing guidance

- In addition, encouraging GP practices to work with the NHS Improvement Tool - GRASP - AF (Guidance on Risk Assessment and Stroke Prevention for Atrial Fibrillation) to identify patients with AF at high risk of a stroke that are currently not properly anti-coagulated as potential candidates for NOACs

(iv) NHS Cornwall Health Community (Education)

- Prescribing of new NOACs discussed at the Area Prescribing Committee

- Development of prescribing guidance stating that warfarin remains first line option but noting that dabigatran can be considered for patients with AF not taking warfarin for reasons of intolerance, previous significant adverse effects with warfarin, interactions, circumstances where routine monitoring may be impractical, and those with AF with poor INR control on warfarin

- Prescribing of dabigatran (and other new NOACs) monitored monthly and reported back to GPs during forum meetings between prescribing advisers and GPS 


\section{Table A1 | Continued}

\section{Country Date dabigatran Summary of activities

(v) NHS Lancashire/ NHS Cumbria (Education, economics):

- Developed a consensus statement for NOACs together with NHS Cardiac and Stroke Networks in Lancashire and Cumbria. This included:

- On the balance of risks and benefits suggest warfarin is considered for high risk atrial fibrillation patients i.e., those with CHADS2 $>2$. Where CHADS2 $<2$, risk assess using CHA2DS2VASc and reconsider the need for anticoagulation.

- NOACs are recommended as an option where warfarin is either contraindicated or where the patient has a documented hypersensitivity to or intolerance of coumarin anticoagulants severe enough to cause treatment withdrawal. In situations where repeated INR testing/monitoring may be impractical, the use of a NOAC should be considered. However, increased bleeding risk as a contraindication to warfarin also applies to NOACs.

- An assessment of bleeding risk should be considered before starting anticoagulation. The HAS-BLED score is recommended to assess bleeding risk in AF patients, however, remember stroke and bleeding share risk factors.

- For patients who are already taking warfarin, the potential risks and benefits of switching to a NOAC should be considered in light of their level of INR control. Where patients are spending over $65 \%$ of their time in the therapeutic range (TTR) on warfarin, there is likely to be little benefit in switching to a NOAC.

- For new patients requiring anticoagulation, warfarin should be considered and, after an informed discussion with the patient, should be initiated with its effectiveness assessed after 3 months of treatment.

- The decision about whether to start a NOAC should be made after an informed discussion between the clinician and the patient about the risks and benefits of NOACs compared to warfarin. Patient Decision Aids are being developed by the Medicines and Prescribing Centre (NPC of NICE) and their use is endorsed by this consensus group.

- Whilst NOACs have a shorter half-life than warfarin, they have no simple antidote. Whilst they don't need anticoagulation monitoring, there is no standardised easy way of measuring their effectiveness. Conversely, warfarin has been in use for over 60 years, its effects are measurable and can be rapidly reversed in the event of major bleeding

- NHS Lancashire and NHS Cumbria also produced guidance for the prescribing of dabigatran. This included:

- Contraindications

- Advice on how to convert patients from warfarin to dabigatran and conversion from dabigatran to warfarin

- Interactions with other medicines

- Advice on the discontinuation of dabigatran based on renal function

- Potential rebate schemes were initially discussed to reduce the costs of dabigatran to NHS

Lancashire. However, this was not taken forward with the change to a Clinical Commissioning Group

Estonia Not reimbursed Dabigatran rejected for this indication as not seen as sufficiently cost-effective versus warfarin in view of its high acquisition costs 
Table A1 | Continued

\begin{tabular}{ll}
\hline Country & $\begin{array}{l}\text { Date dabigatran } \\
\text { reimbursed for AF }\end{array}$
\end{tabular}

Finland April $2012 \quad$ Post-launch (enforcement)

(Martikainen et al.,

Reimbursement restrictions (Enforcement) - limiting the reimbursement of dabigatran to patients with risk

2010; Godman factors where satisfactory control has not been reached with warfarin; alternatively, warfarin cannot be et al., 2011a) prescribed due to side-effects or contra-indications.

Enforcement at the pharmacy with on average 16 days needed for requests to be centrally reviewed and authorised. $100 \%$ co-pay without authorisation.

\begin{tabular}{|c|c|}
\hline France (Sermet & ASMR Rating \\
\hline etal., 2010; & February 2012 \\
\hline Godman et al., & \\
\hline 2012a; Haute & \\
\hline Authorite de Sante & \\
\hline - Commission de la & \\
\hline Transparence, 2012) & \\
\hline
\end{tabular}

Peri-launch

Dabigatran classified as ASMR V (no additional therapeutic value) compared with current therapies for the prevention of strokes in adults at risk who have "non-valvular atrial fibrillation" and are considered to be at risk of stroke.

\section{Post-launch}

(a) April 2012 - Education:

(i) Publication of information about dabigatran from the authorities including a warning from the medicine agency ANSM (ex afssaps):

- risk of haemorragia and overdose

- absence of biological tests and an antidote

(ii) Publication of advice for (1) change of prescribing from or to other anticoagulants, (2) patients undergoing surgery

(b) May 2102

Translation of the latest advice from the EMA

Once reimbursed, patients will be followed up to assess the effectiveness and safety of dabigatran in practice (pharmacovigilance)

Germany (IQWiG, August 2011

2010;

Kreatinin-Clearance

Rechner (Creatinine

Clearance

calculator), 2013)

\section{Peri- and post-launch}

Activities (education and engineering) included the following:

- Information from State and National Physician Associations to ambulatory care physicians stressing concerns and potential sanctions with "off label" use in AF prior to its licensing approval

- Physician Associations stressing when launched that the current knowledge regarding safety with dabigatran was insufficient to answer all questions, and physicians should be careful with prescribing particularly in the elderly

- The reporting of deaths from excessive bleeding further endorsed these concerns. As a result, limited prescribing in practice in ambulatory care

- A warning letter from Boehringer Ingelheim following issues and deaths from excessive bleeding in Japan. In the letter, BI stated that patients should not be prescribed dabigatran if their creatinine clearance is $<30 \mathrm{ml} / \mathrm{min}$ and/ or significant renal impairment. In addition, the need to monitor renal function when using dabigatran especially in patients prone to poor renal function or where renal function is deteriorating (measured using the Cockroft-Gault formula)

- Information to patients about anti-coagulation in general including dabigatran 
Table A1 | Continued

\begin{tabular}{ll}
\hline Country & $\begin{array}{l}\text { Date dabigatran } \\
\text { reimbursed for AF }\end{array}$ \\
\hline
\end{tabular}

Ireland (National July $2012 \quad$ Peri-and post-launch

Centre for Pharma-

August 2011: The National Centre for Pharmacoeconomics (NCPE) stated that "dabigatran etexilate could coeconomics, 2011; be considered a cost effective treatment for the prevention of stroke and systemic embolism for adult Burke, 2012; Health patients with atrial fibrillation and one or more of the specified risk factors. However there are uncertainties Service Executive (HSE) Ireland. Primary Care Reimbursement Service (PCRS) Online Services, 2012) associated with some of the clinical input data and the model assumptions in addition to the considerable opportunity cost, in the region of $€ 13$ million over 10 years." In view of this a reduction in price is recommended to ensure value for money for the health service in Ireland (HSE).

November 2011: A HSE Statement advises that the drug will not be reimbursed if prescribed for any new patients for SPAF (Stroke prevention in patients with AF).

July 2012: A HSE Statement states that:

Warfarin is the recommended first line agent for stroke prevention in atrial fibrillation. Dabigatran should be reserved for:

- Existing patients on warfarin with poor INR control despite adhering to monitoring and lifestyle requirements. Documentation of attempts to optimise warfarin therapy is required.

- Existing patients who require regular periodic treatment with medicines that are known to interact with warfarin

- Patients with a documented allergy to warfarin

As part of the implementation, the physician responsible has to make a specific application for each patient to HSE. Otherwise, pharmacists will not be reimbursed for dispensing dabigatran to patients for SPAF without prior reimbursement approval (enforcement)

October 2012: Following the NCPE pharmacoeconomic assessment (August 2011), the manufacturer reduced the price of dabigatran. At this revised price, the NCPE now considers dabigatran to be cost effective in this situation

Italy (Adamski et al., Undergoing

2010; Cheema evaluation

et al., 2012; Jommi,

2012; Siviero et al., 2012)

\section{Pre-launch}

- Educational meetings at regional and national level with different stakeholders to (i) identify possible prescriber(s) (cardiologists only or GPs as well) and the target population; (ii) define a sustainable price and (iii) define the features of a follow-up programme for patients treated with dabigatran

- Forecasting the potential budget impact in the first and second year post-launch with the help of key stakeholder groups

Post-launch

- Planning a national registry containing details of the clinical characteristics, current pharmacological treatments, and potentially outcomes of patients with AF prescribed dabigatran

- To limit the prescribing to specialists only (cardiologists, others) and to involve the GPs in the follow-up of treated patients;

- To network prescribers (specialists) and GPs as well as instigate educational activities among specialists (prescribers) and GPs according to their needs 
Table A1 | Continued

\begin{tabular}{|c|c|c|}
\hline Country & $\begin{array}{l}\text { Date dabigatran } \\
\text { reimbursed for AF }\end{array}$ & Summary of activities \\
\hline $\begin{array}{l}\text { Netherlands } \\
\text { (Medicine Balance } \\
\text { [MEDICIJNBAL- } \\
\text { ANS], } \\
\text { 2012) }\end{array}$ & December 2012 & $\begin{array}{l}\text { Peri- to post-launch(education, economics) } \\
\text { - The National Health Council advised the Ministry of Health to reimburse dabigatran (and rivaroxaban) but } \\
\text { additional research concerning the specific Dutch situation was needed. The research should be } \\
\text { performed in the real world population seen in clinical in practice } \\
\text { - The Ministry of Health subsequently asked prescriber organizations to establish a guideline for the safe } \\
\text { and responsible introduction of dabigatran. The guideline to contain a protocol for calamities, prioritized } \\
\text { patient groups (which groups are high priority) and instructions to contribute to a patient registry } \\
\text { - The national guideline has now been produced. Each hospital is expected to produce its own protocol } \\
\text { based on the national guidance as well as make arrangements with GPs and ambulance services } \\
\text { - As part of reimbursement, the Ministry of Health sought a price-volume agreement with the } \\
\text { manufacturer } \\
\text { - In addition, a review has been made available by the Institute for the Rational Use of Medicines giving } \\
\text { an overview of the current evidence surrounding dabigatran in AF for physicians. Experts are being used } \\
\text { to initiate online discussions on the new website from this institution to further enhance appropriate } \\
\text { prescribing (Education) }\end{array}$ \\
\hline
\end{tabular}

Norway January $2013 \quad$ Peri-launch

- Dabigatran was recently assessed by the National Medicines Agency of Norway (NOMA) and considered to be cost-effective for the prevention of stroke in adults with non-valvular AF

- The Ministry (as of October 2012) favoured the reimbursement of dabigatran from 1 January 2013, and the Budget Bill was voted in on 5 December 2012

- No ongoing activities such as price: volume agreements or educational activities

$\begin{array}{ll}\begin{array}{l}\text { Poland (Agencja } \\ \text { Oceny Technologii }\end{array} & \text { The Transparency Council of the Polish HTA Agency assessed dabigatran for its potential inclusion in the } \\ \text { Medycznych Rada } & \text { national reimbursement list } \\ \text { Przejrzystości, } & \text { The Transparency Council subsequently rejected reimbursement due principally to safety concerns. The } \\ \text { 2012) } & \text { Council was concerned about the number of serious bleeds and deaths that had already occurred in the } \\ & \text { United States and New Zealand soon after its launch in these countries. }\end{array}$

$110 \mathrm{mg}$ (when PL

granted)
Portugal August 2011 for

- Reimbursed for $110 \mathrm{mg}$ for the prevention of stroke in patients with atrial fibrillation once approved by EMA, as already reimbursed for prophylaxis in patients undergoing hip and knee surgery (current legislation in Portugal). As a result, appreciably increasing utilisation of $110 \mathrm{mg}$ strength

- $150 \mathrm{mg}$ is currently not reimbursed for $\mathrm{AF}$, but is undergoing evaluation alongside an accompanying pharmacoeconomic study versus warfarin which was submitted by the manufacturer to demonstrate the cost-effectiveness of $150 \mathrm{mg}$ dabigatran versus warfarin

- Ongoing activities to lower the reimbursed acquisition cost (price) for AF patients for the $110 \mathrm{mg}$ strength

The Republic of Not reimbursed

Serbia

Dabigatran is currently not reimbursed in Serbia principally due to concerns with its price/ budget impact versus warfarin for the prevention of stroke in patients with AF and the perceived limited benefits in practice.
Republic of Srpska Not currently reimbursed
- The manufacturers made a submission to the Health Insurance Fund (HIF)

- The submission has been reviewed by the HIF and proposed for inclusion in the reimbursement list

- However to date, there has been no decision to include dabigatran in the reimbursed list of drugs 
Table A1 | Continued

$\begin{array}{ll}\text { Country } & \begin{array}{l}\text { Date dabigatran } \\ \text { reimbursed for AF }\end{array}\end{array}$

\section{Scotland (NHS}

August 2011

Tayside, 2011; Fife

Area Drug and

Therapeutics

Committee (2012);

Health

Improvement

Scotland (2012);

NHS Highland - The

Pink One (2012);

Scottish Medicines

Consortium, 2011;

Oral anticoagulants,

2012; Marshall

et al., 2013)

\section{Peri-launch}

National (SMC) - Dabigatran is accepted for use in accordance with the approved indication as it was seen to be at least as effective as standard oral anticoagulation at preventing stroke or systemic embolism and was not associated with an increased risk of major bleeding.

Post-launch (among the Health Boards) (educational)

(a) Fife (December 2011)

Dabigatran should only be prescribed in line with advice from Healthcare Improvement Scotland, i.e., on balance of risks and benefits of dabigatran, warfarin remains the anticoagulant of clinical choice for moderate or high risk atrial fibrillation patients (CHA2DS2-VASc $=2$ ) with good INR control, and clinicians should only consider prescribing dabigatran in patients with:

- poor INR control despite evidence that they are complying, or

- allergy to or intolerable side effects from coumarin anticoagulants

(b) Highlands (December 2011)

- Warfarin remains the anticoagulant of choice as a greater rate of GI bleeding and GI symptoms with dabigatran

- In addition, much easier to manage major bleeding in patients with warfarin as no licensed product available to reverse bleeding with dabigatran (unlike warfarin)

- If needed, dabigatran should only be started when patient's INR has dropped below 2

(c) Tayside (December 2011)

- Prescribing should be restricted to patients with poor INR control on warfarin, or with allergy to or intolerable side-effects from coumarin anticoagulants

- Under the guidance, anticoagulant clinics in NHS Tayside will identify eligible patients and make contact with relevant GPs with the decision to transfer patients resting with GPs

- In addition, prescribers should note recent MHRA advice that renal function should be assessed in all patients before starting dabigatran. While on treatment, renal function should be assessed at least once a year in patients $>75$ years and when a decline in renal function is suspected

(d) Lothian (May 2012 Bulletin)

- Dabigatran classified as "not preferred as suitable alternatives exist."

- The main concerns were safety and the management of any bleeding episodes when they occur

Slovakia April $2012 \quad$ Peri-launch

- Dabigatran was assessed by the Categorisation Committee at the Slovak Ministry of Health and considered cost-effective for the prevention of stroke in adults with non-valvular AF. The incremental cost-effectiveness ratio (ICER) of dabigatran versus standard treatment was estimated at $€ 17,437$, which is below the Slovakian acceptable threshold (€18,000 per QALY gained). The sensitivity analysis consistently demonstrated the cost-effectiveness of dabigatran.

- Only reimbursed if prescribed by cardiologists, neurologists or internists in line with the approved indications (enforcement). One of the following requirements are also needed for reimbursement in all indications apart from a previous stroke, TIA or systemic embolism:

- Chronic warfarin treatment is not properly controlled in the therapeutic range INR 2-3, and 2 out of 6 INR values are out of this range, or

- During the first 3 months of warfarin treatment, INR 2-3 is not reached, or warfarin is contraindicated

Post-launch

- Demand-side activities included local, regional and national events to discuss the reimbursed indications and the care needed to prescribe dabigatran (education) 


\section{Table A1 | Continued}

\begin{tabular}{|c|c|c|}
\hline Country & $\begin{array}{l}\text { Date dabigatran } \\
\text { reimbursed for AF }\end{array}$ & Summary of activities \\
\hline Slovenia & August 2012 & $\begin{array}{l}\text { Peri-launch } \\
\text { Reimbursement in line with the licensed indication in conjunction with a complex price: volume agreement } \\
\text { Post-launch } \\
\text { Demand-side activities included: } \\
\text { - Education of all involved specialists and primary care physicians on key safety aspects/ adverse events } \\
\text { with dabigatran } \\
\text { - Prescribing restrictions (Enforcement) } \\
\text { Only reimbursed if initiated by an internist or neurologist in line with approved indications. This also } \\
\text { includes patients already on warfarin who have unstable anticoagulation, i.e., TTR < } 65 \\
\circ \text { Patients have to be followed in a tertiary or secondary care anticoagulation centre. Patients can be } \\
\text { treated in primary care but only if authorized by the tertiary or secondary care centre. } \\
\circ \text { Every patient has to be registered in a database and followed by the IT anticoagulation programme } \\
\circ \text { Anticoagulation centres have to report once yearly to the tertiary centre regarding the number of } \\
\text { patients experiencing minor and major bleeding, thromboembolic events, as well as any deaths from } \\
\text { bleeding or thromboembolism }\end{array}$ \\
\hline
\end{tabular}

Spain (Coma etal. N November 2011 2009; Ostazen, 2011)
(A) Post-launch activities (Basque Country)

(a) Assessment

- General evaluation of dabigatran in the prevention of thromboembolism in patients with AF performed by the Drug Assessment and Vigilance Unit CEVIME of the Drug Directorate of the Ministry of Health of the Basque Country. This included a budget impact analysis under three scenarios. The budget impact for 2012 was estimated as 1.5\% (7M€) of the total expenditure of primary care health prescriptions in the most restricted scenario.

- A consensus statement (education) coordinated by the Ministry of Health, in collaboration with the Professional Societies of Family Physicians, Hospital and Primary Care Pharmacologists, Haematology and Haemotherapy, Cardiology, Internal Medicine and Neurology, resulted in the following restrictions for dabigatran:

- Existing patients previously treated with vitamin $\mathrm{K}$ antagonists (VKA) where there is hypersensitivity to acenocoumarol, warfarin or other coumarin, when INR levels cannot be properly monitored, with abnormal INR levels or when the INR is in the correct range but thromboembolic or haemorrhagic episodes are common

- New Patients: In patients with a history of ischemic stroke or high risk of intracranial haemorrhage otherwise second line after VKAs

- A post-marketing authorisation analysis is being performed by the Ministry of Health of the Basque Country to assess the actual budget impact of dabigatran

- Distribution of the consensus document (education) among all healthcare professionals (primary and specialized care) and inclusion in the common electronic medical record educational tools (all the professionals have access to this medical record in primary and specialised care) 


\section{Table A1 | Continued}

\section{Country Date dabigatran Summary of activities

(b) Engineering/ enforcement

- Routine scrutiny of the prescribing dabigatran to ensure its rational use in the Basque Health System, according to the provisions of the Spanish Royal Decree 618/2007 of May 11th. Reimbursement/ funding is controlled by the Medical Inspection of the Ministry of Health of the Basque Country, with funding only granted for the prevention of stroke and systemic embolism in adult patients with non-valvular atrial fibrillation with one or more of the following risk factors: (a) Stroke, transient ischemic attack, or prior systemic embolism (ES); (b) Left ventricular ejection fraction $<40 \%$; (c) Symptomatic heart failure Class 2 or greater under the scale New York Heart Association (NYHA); (d) Age greater than or equal to 75 years; (e) Age greater than or equal to 65 associated with one of the following: diabetes mellitus, coronary heart disease or hypertension. In addition, meeting the above consensus criteria. This has helped to conserve its use in practice

- The Ministry of Health of the Basque Country has included in its contracts with providers (primary and secondary care) quality of care indicators. This includes new drugs where there are concerns with their value versus existing gold standards, which now includes dabigatran. The list is updated annually and managed by the Basque Provinces directorates.

- Prescriptions are electronically controlled by the Drug Directorate of the Ministry of Health of the Basque Country, and their standardized variability analysed.

(c) Post-launch activities also included (education, engineering)

- A centralized post-marketing authorisation follow-up of all patients receiving dabigatran

- Data on patients prescribed dabigatran for AF are regularly being sent from pharmacists and clinical pharmacologists to the Ministry of Health Directorates. This electronic tool allows primary health care physicians to self-audit their prescribing and the region to monitor dabigatran use

(B) Post-launch activities (Catalonia)

(a) Education

- General evaluation of dabigatran in the prevention of thromboembolism in patients with AF performed by the Catalan HTA.

- A second evaluation undertaken by the DTC of the Catalan Institute of Health $(\mathrm{ClH})$ resulted in a more restricted patient population, i.e., only in atrial fibrillation patients with (i) prior acenocumarol treatment and lack of control of INR values (2-3) in more than $60 \%$ of the last assessments, in spite of good adherence to treatment, (ii) patients who have difficulties to follow INR control and (iii) those with an allergy to acenocumarol

- A third evaluation is currently being undertaken by the Catalan HTA to evaluate the different drugs available and their potential use for the prevention of thromboembolism

- Distribution of a document describing the DTC decision to all Primary Health Care (PHC) physicians, as well as electronic notices and warnings regularly published on physician computers (100\% of PHC physicians use computers). The same documents also distributed to hospital DTCs as well as Cardiology, Neurology, Internal Medicine and Haematology clinics.

(b) Engineering

- Catalan Health Service contracts with providers (primary and secondary care) to incorporate quality of care indicators including new drugs where there are concerns with their value versus existing gold standards. This now includes dabigatran, with the list updated annually 


\section{Table A1 | Continued}

\section{Country Date dabigatran Summary of activities

(c) Economics

- There are financial incentives for Catalan Health Service providers aimed at limiting the prescribing of new premium priced drugs with limited health gain versus current standards, with pertinent indicators included in the current range of quality of care indicators

- Physicians who do not attain agreed standards do not receive the financial incentive

Post-launch activities (education, engineering) also included:

- A centralized follow-up of all patients prescribed dabigatran has been established in the ClH. Patients' age, previous treatment with oral anticoagulants or antiplatelet agents, renal function and previous history of ischemic heart are monitored

- Patients at risk of bleeding because of abnormal or unknown renal function, or with inadequate dabigatran prescriptions, are identified. Physicians in charge of these patients are contacted to confirm whether the indication for dabigatran conforms to $\mathrm{CIH}$ guidance and whether patients could be changed to acenocumarol

- Data on patients using dabigatran for AF are regularly sent to PHC pharmacists and clinical pharmacologists, hospitals and CIH DTCs. This electronic tool allows primary health care physicians to self-audit, and the region to monitor dabigatran use

- A qualitative prescription study is also currently being performed among PHCs in Barcelona. All patients prescribed dabigatran during the last semester of $2011(n=331)$ will be followed for 12 months. The objective is to evaluate dabigatran's effectiveness and adverse effects in practice.

Sweden (Godman

et al., 2009c, 2012d;

Holmström et al.,

2009; Janusinfo,

\section{9; Stockholms}

läns landsting,

2011; Janusinfo,

2012a; Medicin \&

Läkemedel, 2012;

Östergötland, 2012;

Davidson et al.,

2013), SBU

(Swedish Council

on Health

Technology

Assessment, 2011)
November 2011

(I) National - peri-launch

- SBU alert advisory report containing a statement that dabigatran seems to be no better than warfarin when applied to Swedish health care system

- TLV did not introduce any prescribing restrictions when authorising reimbursement for dabigatran

- Follow-up of patients in registries

(II) Regional/ County activities

(i) Östergötland County Council

Pre-launch activities (educational, economics)

- Update of the previous report on the prevalence of atrial fibrillation In Östergötland

- Establishing a working party with broad representation from the departments of cardiology and internal medicine, primary health care, representatives from the warfarin polyclinics, epidemiologist and health economists associated with the Drug and Therapeutics Committee (DTC)

- Scientific publication of the cost-effectiveness model for dabigatran for the prevention of stroke based on Östergötland by the Centre for Medical Technology Assessment, Linköping University, in collaboration with Östergötland County Council

- Consensus action plan agreed 12 months before dabigatran was registered for the prevention of stroke in patients with AF

- Recommendation from the DTC to classify dabigatran as a "focus-drug," i.e., the prescribing unit will be responsible for the cost of the drug. If however patients are entered into the County Council's quality assessment program, the cost will be borne by the County Council

- Decision by the County Council to follow the recommendation of the DTC

- Resources for treating patients allocated in the 2011-2012 drug budget

- Communication plan implemented 


\section{Table A1 | Continued}

\begin{tabular}{|c|c|c|}
\hline Country & $\begin{array}{l}\text { Date dabigatran } \\
\text { reimbursed for AF }\end{array}$ & Summary of activities \\
\hline & & 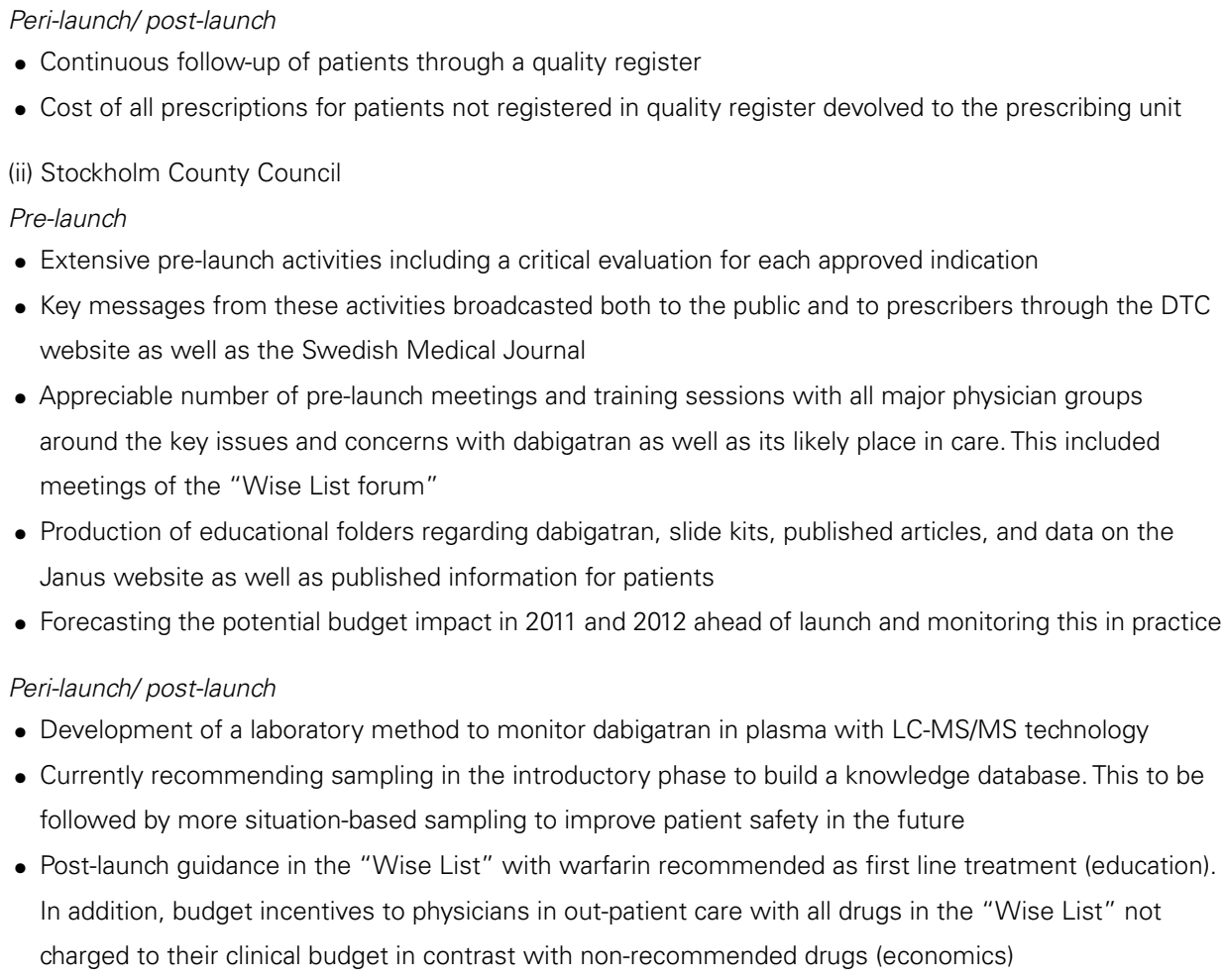 \\
\hline Turkey & Not reimbursed & $\begin{array}{l}\text { - Currently only reimbursed (75 mg) for prophylaxis in patients undergoing elective hip (maximum } \\
35 \text { days) or knee (maximum } 10 \text { days) replacement, and only reimbursed with special authorised reports } \\
\text { from orthopaedic surgeons (initial); subsequent follow-up prescriptions only reimbursed via orthopaedic } \\
\text { surgeons and subject to co-pay (enforcement) } \\
\text { - } 110 \text { and } 150 \text { mg currently not reimbursed (100\% co-pay) }\end{array}$ \\
\hline
\end{tabular}

